\title{
Integration of Indocyanine Green Analogs as Near-Infrared Fluorescent Carrier for Precise Imaging-Guided Gene Delivery
}

\author{
Hong Liang, Xiaobing Chen, Rongrong Jin, Bowen Ke,* Matthias Barz, Hua Ai, and Yu Nie*
}

Codelivery of diagnostic probes and therapeutic molecules often suffers from intrinsic complexity and premature leakage from or degradation of the nanocarrier. Inspired by the "Y" shape of indocyanine green (ICG), the dye is integrated in an amphiphilic lipopeptide (RNF). The hydrophilic segment is composed of arginine-rich dendritic peptides, while cyanine dyes are modified with two long carbon chains and employed as the hydrophobic moiety. They are linked through a disulfide linkage to improve the responsivity in the tumor microenvironment. After formulation with other lipopeptides at an optimized ratio, the theranostic system (RNS-2) forms lipid-based nanoparticles with slight positive zeta potential enabling efficient condensation of DNA. The RNS- 2 displays glutathione responded gene release, activatable fluorescence recovery, and up to sevenfold higher in vitro transfection than Lipofectamine 2000. Compared with a Cy3 and Cy5 labeled fluorescence resonance energy transfer indicator for gene release, the "turn-on" indocyanine green analogs exhibit longer emission wavelength and better positive correlation with the dynamic processes of gene delivery. More importantly, the RNS-2 system enables efficient near infrared imaging guided gene transfer in tumor-bearing mice and thus provides more precise and accurate information on location of the cargo gene and synthesized carriers. the aim by themselves, for the nucleic acids are anionic biomacromolecules that cannot be spontaneous translocated through cell membrane. Cellular entry, lysosome degradation, and nuclear pore traverse are great obstacles during the transport processes. Thus, gene delivery vehicles are critical. Positively charged synthetic vectors (such as cationic polymers, lipids and amino acids) are generally used to condense nucleic acid via electrostatic interaction into appropriate sized nanoparticles for efficient endocytosis. More and more cationic carriers with well-defined structures have been fabricated to explore the structure-activity relationship, which was closely associated with the gene transfection efficiency. ${ }^{[1]}$ In addition, microenvironment (such as $\mathrm{pH},{ }^{[2,3]}$ reduction, ${ }^{[4,5]}$ reactive oxygen species, ${ }^{[6,7]}$ and adenosine triphosphate ${ }^{[8,9]}$ ) stimuli-responsive moieties were applied to induce sensitive deshielding, ${ }^{[10-12]}$ charge conversion, ${ }^{[13,14]}$ disassembly, ${ }^{[15]}$

\section{Introduction}

Gene therapy has made remarkable progress in the cure of genetic disorders and cancer. Successful gene therapy requires transport of sufficient amount of nucleic acids (pDNA, mRNA, siRNA, etc.) inside cell, reaching to the nuclei or cytosolic compartments. However, genetic substances hardly realize

Dr. H. Liang, X. Chen, Dr. R. Jin, Prof. H. Ai, Prof. Y. Nie

National Engineering Research Center for Biomaterials

Sichuan University

Chengdu 610064, P. R. China

E-mail:nie_yu@scu.edu.cn

Prof. B. Ke

Laboratory of Anesthesiology and Critical Care Medicine

Department of Anesthesiology

Translational Neuroscience Center

West China Hospital

Sichuan University Chengdu

Sichuan, Chengdu 610041, P. R. China

E-mail: bowenke@scu.edu.cn

Dr. M. Barz

Institute of Organic Chemistry

Johannes Gutenberg-University Mainz

Duesbergweg 10-14, 55099 Mainz, Germany

The ORCID identification number(s) for the author(s) of this article can be found under https://doi.org/10.1002/smll.201906538.

DOI: 10.1002/smll.201906538 and configuration change ${ }^{[16]}$ for better biomimic and delivery process optimization. We have also designed and synthesized a series of amino acid derivatives, including amphiphilic lysine/ histidine/arginine dendrimers, ${ }^{[17]}$ amino acid functionalized polysaccharides, ${ }^{[18]}$ and arginine-rich nanohybrids with hierarchical response or targeting, ${ }^{[13]}$ which have been demonstrated to achieve enhanced delivery efficiency of genes or drugs. However, there are still many unclear processes, such as undesirable accumulation, inappropriate elimination, serious immune response, and premature degradation of the delivery system, which may reduce the therapeutic effect, especially the final transfection in vivo. Therefore, we need to develop a technique for the in vivo fate understanding of gene delivery systems. What happens to them and how the therapeutic agents is really delivered?

In order to answer these questions, accurate and precise in vivo traceability of delivery system is required. Ideally a tracer should allow for an investigation of biodistribution as well as intracellular localization at the same time. In the past decade, theranostic concept provides a promising strategy for simultaneous drug or gene delivery and molecular imaging in a single system ${ }^{[19]}$ and gives a capability to visualize and quantify the pharmacokinetic processes of cellular and molecular therapies (adsorption, distribution, metabolism, and excretion) at both cellular and tissue levels in a real-time fashion. ${ }^{[20,21]}$ Particularly, imaging-guided drug delivery can monitor the path of drugs in vivo, evaluate the 

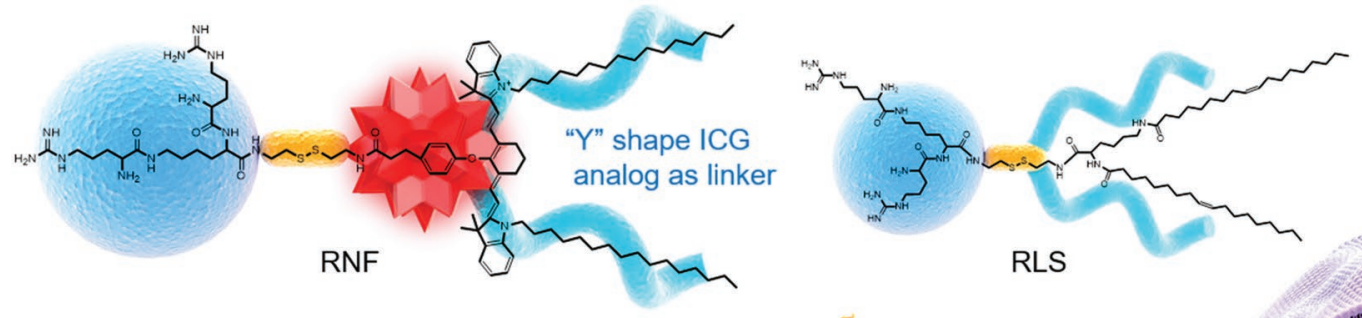

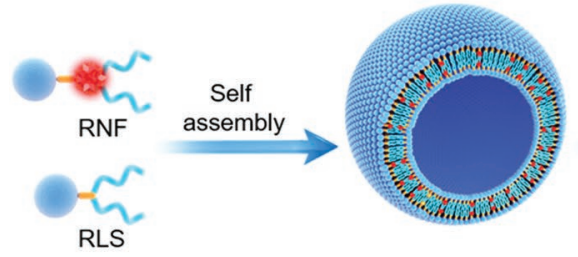

Fluorescent “ON”
Fluorescent "OFF"

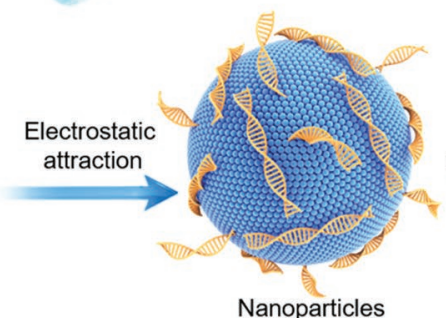

as gene carrier

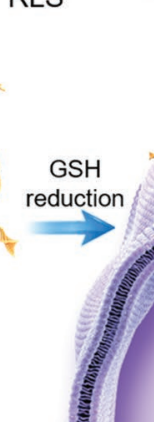

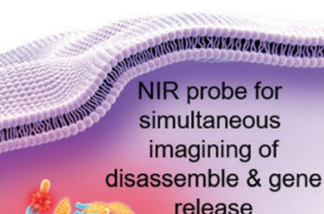

Fluorescent "ON" for real-time image

Scheme 1. Schematic diagram of near-infrared fluorescence theranostic carrier for image-guided gene delivery.

efficiency of tumor-targeted delivery, and further provide information regarding pharmacokinetics of the treatment. ${ }^{[2]}$

Typically, the probes used for imaging are physically encapsulated or chemically bonded to the residual groups of nanocarriers. However, these loading modes for fluorescent nanomaterials often suffer from high nonspecific background and low signal-to-background ratio due to the premature leakage, ${ }^{[23-25]}$ even fluorescence resonance energy transfer (FRET) was used for imaging. Compared with "always-on" probes, the design of activatable theranostic nanomaterials with "turn-on" feature offers an opportunity to reduce the background interference and improve the spatial resolution, ${ }^{[26-28]}$ for it could only switch from "OFF" to "ON" for selective molecules or events. In addition, it was found that the imaging capacity and gene delivery procedure often implemented separately, resulting in low theranostic outcome. ${ }^{[29]}$ Thus, the conjugation linker and the position of probe are factors that cannot be ignored. Predegradation and following nonspecific adsorption events may lead to false positive results. ${ }^{[30]}$ Little information was provided about real carrier metabolic process during the whole therapy, so that timely feedback from the theranostic system is not available.

Therefore, researchers attempted to rationally integrate the fluorescent probe as "main" portion of the carriers. Some amphiphilic drug delivery carriers that taking the advantage of strong hydrophobic properties of boron dipyrromethene (BODIPY) have developed. ${ }^{[20,31,32]}$ And platinated-BODIPY molecules have been designed to combine chemical, photodynamic, and photothermal therapy together for tumor ablation, ${ }^{[33]}$ showing encouraging prospect.

In view of current challenges and inspired by chemical structure of indocyanine green (ICG) which possesses "Y" shape symmetrical group and approvement by The Food and Drug Administration, ${ }^{[34,35]}$ we herein developed a redox-induced "turn-on" system for gene delivery and imaging with real-time visualization of carrier metabolism (Scheme 1). The designed amphiphilic molecules consist of three segments: an argininerich hydrophilic moiety for efficient gene condensation and cytomembrane penetration, a derivative of cyanine dye in the skeleton structure as hydrophobic moiety for fluorescence imaging, and a disulfide bond as trigger for reduction-responsive cargo release at tumor. Furthermore, the fluorescence signal will grow from nothing by the aggregation-caused quenching (ACQ) effect, to gradually increase with the disassembly of nanocarrier systems.

\section{Results and Discussion}

\subsection{Synthesis of Arginine-rich and Near-Infrared Fluorescence Dye-Containing Amphiphilic Dendritic Lipopeptide (RNF)}

Cationic poly-L-lysine, polyethylene imine (PEI), (2,3-dioleoyloxy-propyl)-trimethylammonium lipid, and commercial kits from the lipofectamine family are the most commonly used systems for gene transfection in vitro, but restricted for in vivo application due to their poor serum resistance capacity during the complicated biological environment. Viruses are natural perfect assemblies with nanoscaled core-shell structure and smart configuration adjustment during infection. Therefore, with the development of supramolecular science and inspiration from virus, chemists have designed many new artificial vectors for gene delivery over the last decade. ${ }^{[36]}$ Some amphiphilic molecules, which can self-assemble into nanoparticles and response to microenvironment, provide a convenient approach to mimic viral architectures and functions, indeed improving the gene delivery efficiency. ${ }^{[37]}$ In our previous studies, a series of cationic arginine-rich amphiphilic lipopeptides have been optimized for viral cell-penetrating peptides mimicking, achieving high delivery efficiency in vitro and vivo. ${ }^{[15,38]}$ Meanwhile, we have successfully imitated the viral intelligent regulation by introduction of gradient $\mathrm{pH}$ or reduction responsive moieties in the artificial vectors, obtaining high selectivity in gene transfection. ${ }^{[13,18]}$ In order to go further understanding and optimizing virus-inspired nanomaterials, from our point of view, there is a tremendous requirement for precise and accurate bioimaging on organ and cellular levels. 
Since biodistribution and subcellular distribution are dynamic processes, flourescence imaging seems to be the method of choice in noninvasive optical techniques to study these processes. Among them, near infrared (NIR) fluorescence is widely applied due to its enhanced penetration and weak absorption/scattering properties in tissues, and the ICG has been approved by Food and Drug Administration as an NIR fluorescent contrast agent for in vivo imaging. In order to visualize nanosized delivery systems, organic dyes are typically encapsulated into nanocarriers $^{[39,40]}$ or conjugated to the periphery of materials. ${ }^{[41-43]}$ However, recent studies confirmed that these patterns probably failed to monitor the in vivo fate of carriers because the dyes tend to fall off before reaching the targeted site. ${ }^{[2,44]}$ Therefore, we fabricated an amphiphilic molecule composed of dendritic arginine and cyanine derivative dye (IR-780 molecule), which could implement the fluorophore in the carrier systems itself for combination of bioimaging and gene delivery. In prospecting for better assembly and cellular fusion properties, we introduced two long alkyl chains to IR-780 improving its hydrophobicity, flexibility, and capacity of gene carrier. ${ }^{[45]}$ After self-assembly, the fluorescence would be quenched due to the ACQ effect. While under the reductive condition, the whole amphiphile would disassembly and restore its fluorescent signal, owing to cleavage of the disulfide bond.

The hydrophilic part, containing dendritic arginine, was synthesized using divergent method with lysine as a core, ${ }^{[15,38]}$ while hydrophobic part of cyanine dye was prepared according to the established methodologies. ${ }^{[46]}$ As depicted in Figure 1, compound
2 was used for the condensation reaction with prepared intermediation indolium salt (compound 1) in anhydrous sodium acetate. By employing side chain on the indocyanine backbone, chlorosubstituted fluorophore (compound 3) was successfully synthesized for the next step. The addition of phenoxypropionic acid to the base chlorocyanine dye (compound 3) occurred by nucleophilic substitution of the choloride via an $\mathrm{S}_{\mathrm{N}} 1$ mechanism. This reaction generated the labeling dye (compound 4) as green solid. The disulfide bond containing cystamine (compound 5) as linker was first conjugated with hydrophobic fluorescent molecule to afford intermediate compound 6 with moderate yield in the presence of O-(benzotriazol-1-yl)- $N, N, N^{\prime}, N^{\prime}$-tetramethyluronium tetrafluoroborate (TBTU) and $N, N$-diisopropylethylamine (DIEA). After removal of protective group, the dendron with arginine-rich periphery was covalently bonded to the other end of the linker to generate compound 9 via a condensation between the amino group and carboxyl group. After deprotection, the amphiphilic molecule (RNF) with arginine (R) periphery and near-infrared fluorophore was obtained (Figure 1). More details about the synthesis of target molecule were presented in the Supporting Information. And the crude products were purified by silica column chromatography with gradient elution (methanol/dichloromethane). The chemical structure of each compound was characterized by nuclear magnetic resonance spectroscopy $\left({ }^{1} \mathrm{H}\right)$ and mass spectrum (Figures S1-S8, Supporting Information). The arginine-rich and oleic acid-containing amphiphilc dendritic lipopeptide (RLS), which did not contain fluorophore, was prepared according to the literature. ${ }^{[38]}$
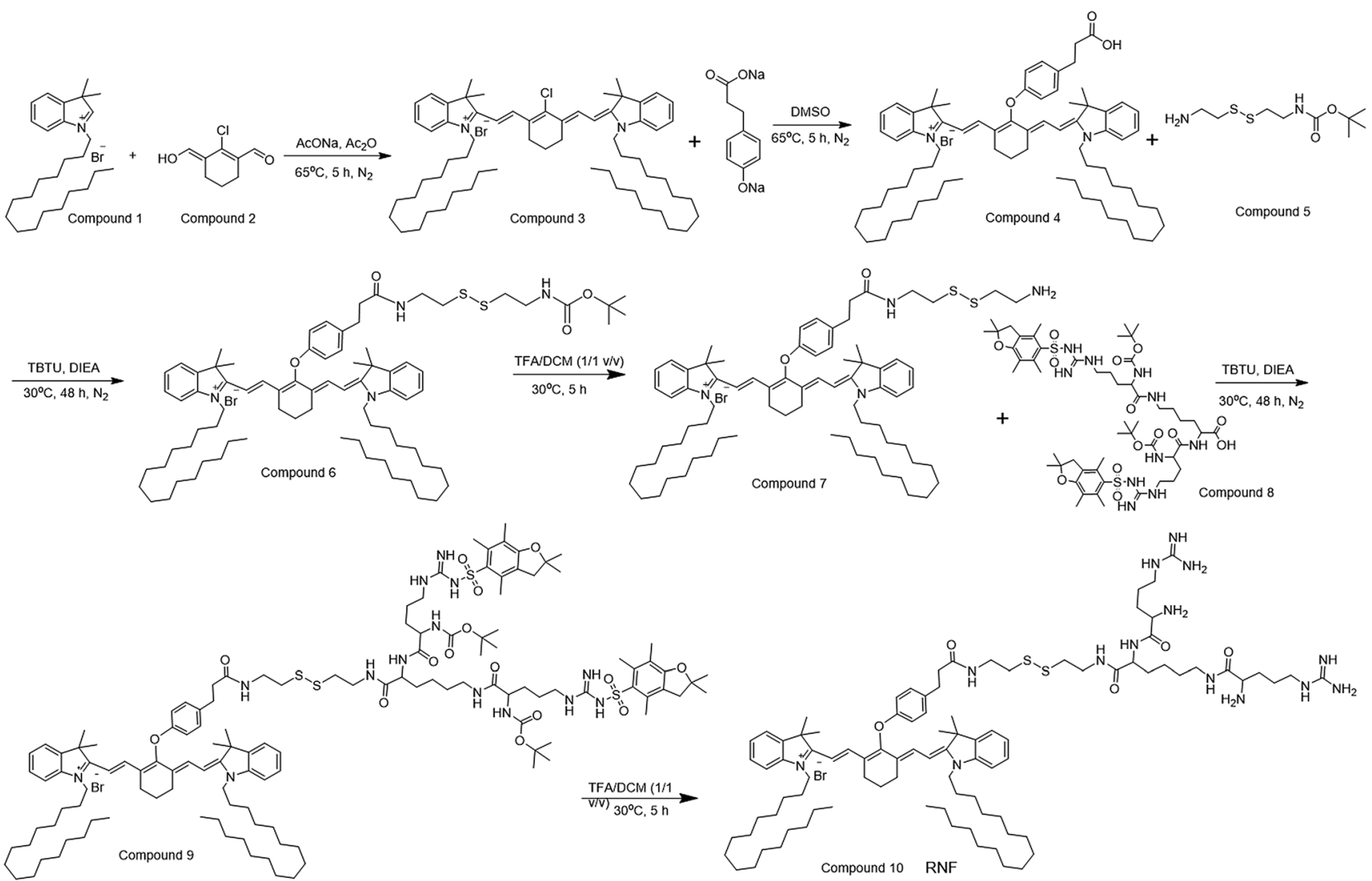

Figure 1. Synthetic routes of indocyanine green analogs integrated amphiphilic dendritic lipopeptide (RNF) as near-infrared fluorescence theranostic carrier. 
Table 1. The size and zeta potential of various assemblies and their gene complexes.

\begin{tabular}{lccccc}
\hline Sample & $\begin{array}{c}\text { Ratio of } \\
\text { RLS/RNF }\end{array}$ & N/P & PDI & $\begin{array}{c}\text { Z-average } \\
{[\mathrm{nm}]}\end{array}$ & $\begin{array}{c}\text { Zeta potential } \\
{[\mathrm{mV}]}\end{array}$ \\
\hline RNF & - & - & $0.28 \pm 0.06$ & $165.8 \pm 1.9$ & $25.7 \pm 1.1$ \\
RLS & - & - & $0.16 \pm 0.01$ & $140.1 \pm 2.7$ & $22.6 \pm 0.1$ \\
RNS-1 & 1 & - & $0.19 \pm 0.04$ & $140.4 \pm 3.1$ & $22.8 \pm 0.1$ \\
RNS-2 & 2 & - & $0.18 \pm 0.05$ & $105.9 \pm 1.2$ & $20.5 \pm 0.7$ \\
RNS-3 & 3 & - & $0.13 \pm 0.02$ & $126.0 \pm 2.1$ & $21.6 \pm 1.3$ \\
RNF/DNA & - & 40 & $0.19 \pm 0.05$ & $201.6 \pm 6.1$ & $22.7 \pm 1.6$ \\
RLS/DNA & - & 10 & $0.15 \pm 0.01$ & $225.5 \pm 2.6$ & $17.5 \pm 0.4$ \\
RNS-1/DNA & 1 & 30 & $0.16 \pm 0.01$ & $193.1 \pm 1.1$ & $20.4 \pm 0.8$ \\
RNS-2/DNA & 2 & 30 & $0.17 \pm 0.02$ & $224.1 \pm 2.4$ & $17.6 \pm 0.1$ \\
RNS-3/DNA & 3 & 30 & $0.18 \pm 0.03$ & $198.3 \pm 5.9$ & $20.8 \pm 1.2$ \\
\hline
\end{tabular}

\subsection{Characterization of Physicochemical Properties}

Based to the size and zeta potential detected by dynamic light scattering (DLS, Table 1), RNF and RLS assemblies containing only single molecule showed the $Z$-average diameter of $\approx 165$ and $140 \mathrm{~nm}$, with zeta potential of 25.7 and $22.6 \mathrm{mV}$, respectively. These slight differences may be attributed to the higher hydrophobicity and rigidity of NIR dye in RNF, which limited flexibility in the self-assembly process. ${ }^{[47]}$ Mixture of RLS an RNF molecules at different mass ratios (RNS-1, RNS-2 and RNS-3) could form nanosized particles with diversified characters. Among the mixed assemblies, the size of RNS-1 and RNS-3 assemblies were about 140 and $126 \mathrm{~nm}$, with surface potential of 22.8 and $21.6 \mathrm{mV}$, respectively. While RNS-2 displayed the minimum size of $105.9 \mathrm{~nm}$ and zeta potential of $20.5 \mathrm{mV}$. The smaller size of assemblies may be attributed to a better packing of individual molecules in the self-assembly process, according to our experience in previous work. ${ }^{[38]}$ The morphology of RNS-2 and RNS-2/DNA (N/P = 30) complexes was observed by transmission electron microscopy (Figure 2A,B), displaying a uniform ellipsoidal shape, although in line with DLS DNA lipoplexes are slightly larger in diameter.

Moreover, we investigated the spectral characteristic of various molecule and assemblies in organic or aqueous solutions to mimic flourescent "ON" and "OFF", respectively. RNF molecule showed the maximal ultraviolet absorption of RNF at $770 \mathrm{~nm}$ in methanol (Figure S9A, Supporting Information), while it displayed maximum fluorescence emission wavelength of $780 \mathrm{~nm}$ in methanol with excitation wavelength of $750 \mathrm{~nm}$ (Figure S9B, Supporting Information). The fluorescence spectra of other assemblies with different formulation ratios can be found in Figure S9B in the Supporting Information. It was obviously that fluorescence of RNF was quenched after being neither self-assemblies alone nor mixed with RLS into nanoparticles, due to ACQ effect. Interestingly, the RNS-2 assemblies have better quenching effect than the others, confirming a tighter and better assembly at this mixing ratio. To demonstrate the turn-on property of fluorescence, the RNS-2 assemblies were incubated with $10 \times 10^{-3} \mathrm{M}$ glutathione and dithiothreitol (DTT) for $1 \mathrm{~h}$ at $37^{\circ} \mathrm{C}$. As expected, fluorescence recovery was observed, almost reaching the level of RNF in methanol, owing to the disassembly caused by disulfide bond breakage (Figure 2C). Similar phenomenon of the fluorescence recovery has also been confirmed by other studies, ${ }^{[48]}$ in which fluorescent dye could be cleaved from the periphery of nanoparticles and the intensity could be restored from the original quenching state.

Next, the disassembly process induced by reductive conditions was verified through the changes in size and zeta potential with time. Various assemblies were incubated with $10 \times 10^{-3} \mathrm{M}$ glutathione for different time period $(0-3 \mathrm{~h})$ at $37{ }^{\circ} \mathrm{C}$. Once the disulfide bond cleaves, the size of assemblies would significantly increase due to the changes in hydrophilichydrophobic properties and aggregation of fragments. ${ }^{[49,50]}$
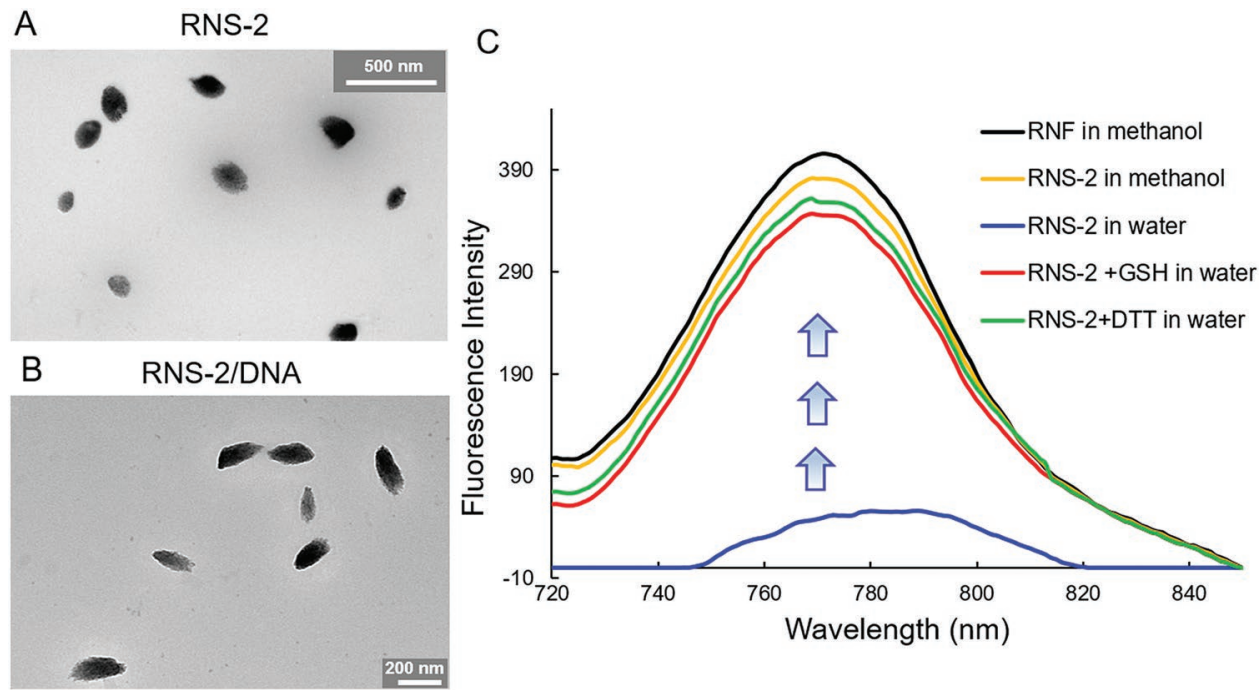

Figure 2. The morphology of A) RNS-2 assemblies and B) RNS-2/DNA (N/P = 30) complexes observed by transmission electron microscope. C) Fluorescence emission spectra of RNF in methanol (black line), RNS-2 assemblies in methanol (orange line), RNS-2 assemblies in water (blue line), RNS-2 assemblies incubating with $10 \times 10^{-3} \mathrm{M}$ glutathione (GSH, red line), and dithiothreitol (DTT, green line) in water for $1 \mathrm{~h}$, excited by the laser with $750 \mathrm{~nm}$ wavelength. 

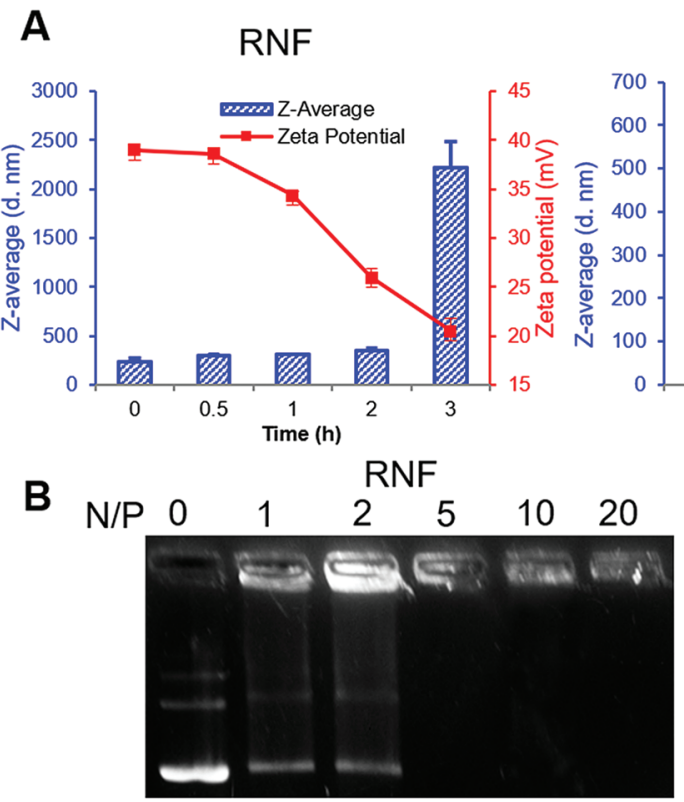

C

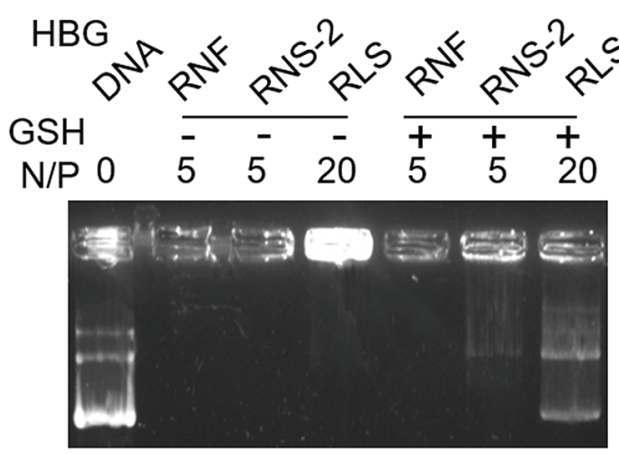

RLS

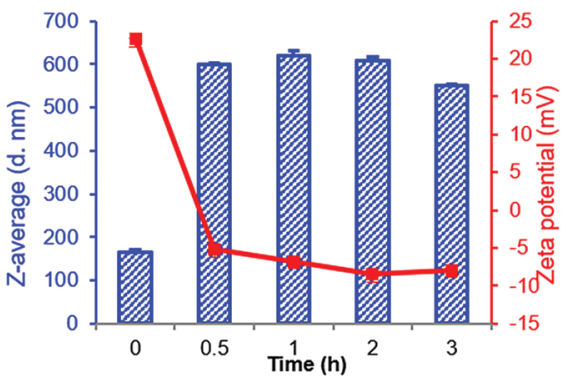

RLS
RNS-2

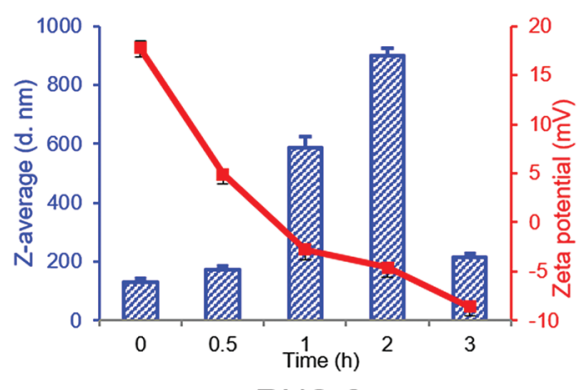

RNS-2
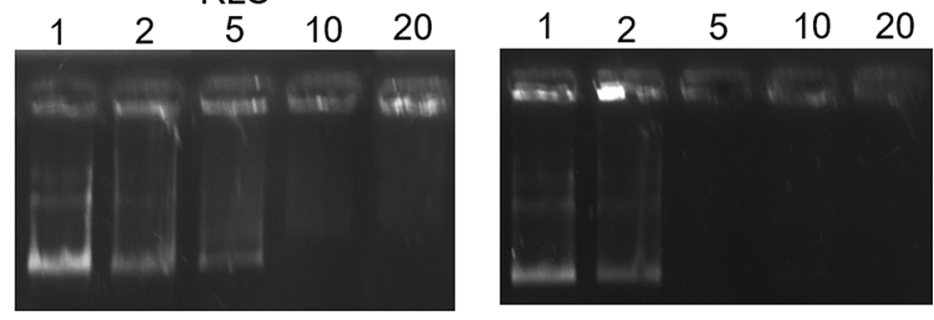

$10 \%$ FBS
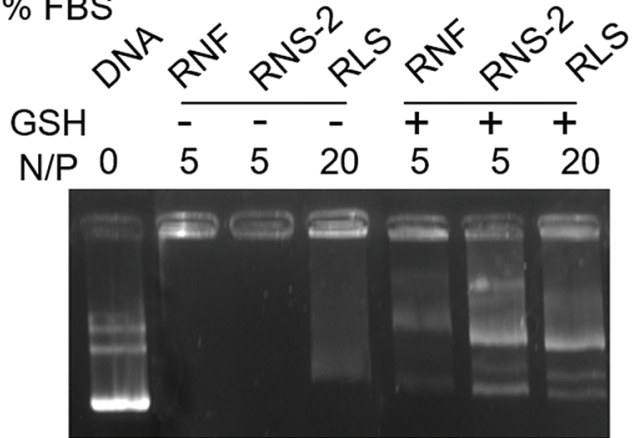

Figure 3. A) The size (blue histogram) and zeta potential (red curve) changes of various assemblies after incubation with $10 \times 10^{-3} \mathrm{M}$ glutathione. Date are presented as means \pm standard deviation (SD, $n=3)$. B) The gene condensation ability of assemblies with different $N / P$ ratios $(N / P=0,1$, $2,5,10$, and 20). C) The gene release ability of assemblies with $10 \times 10^{-3} \mathrm{M}$ glutathione (CSH) in HBG buffer ( $\left.\mathrm{pH}=7.4\right)$ and DMEM culture media containing $10 \%$ FBS.

These results showed that the order of reductive sensitivity was RLS > RNS-2 > RNF (Figure 3A). The $z$-average size of RNF assemblies remained invariant for about $2 \mathrm{~h}$, while size of RLS assemblies could rapidly respond within $30 \mathrm{~min}$ and diameter of RNS-2 assemblies gradient increased within $1 \mathrm{~h}$. The longer response time of RNF or RNF-containing assemblies might due to the rigidity structures of dyes, which reduced the flexibility of assemblies like the function of cholesterol in liposome. ${ }^{[51,52]}$ Lower flexibility could prevent the penetration of small molecule (like GSH). Naturally, the response speed of the mixed assemblies (RNS-1, RNS-2, and RNS-3) increased with increasing RLS ratio (Figure S10A,B, Supporting Information). Meanwhile, the zeta potential of all assemblies went down gradually and the variation trend was similar as that of size. The results were consistent with previous reports that the zeta potential of cationic assemblies would be sharply reduced with destruction of the structure. ${ }^{[13,18]}$

Gene release is considerable vital for efficient transfection. ${ }^{[53]}$ Whether the disassemble of particles would simultaneously result in a release of gene like the viral systems was verified by gel electrophoresis. It was clear that all assemblies including RNF, RLS, and RNS-2 could efficiently condense gene at low N/P ratio (Figure $3 \mathrm{~B}$ ). And then, the gene complexes were incubated with $10 \times 10^{-3} \mathrm{M}$ glutathione for $2 \mathrm{~h}$ at $37{ }^{\circ} \mathrm{C}$ either in the HBG buffer (HEPES $20 \mathrm{mM}, \mathrm{pH} 7.4,5 \%$ glucose) or $10 \%$ fetal bovine serum (FBS) medium, in order to simulate biological body fluid and emulate the environment of blood fluid in vivo (Figure 3C). As expected, DNA could be easily released from RLS assemblies in both two situations. In the HBG buffer solution, gene was hardly released from the RNF assemblies, while the release from RNS-2 assemblies was inconspicuous. In $10 \%$ FBS medium, gene was still relatively hard to release from RNF assemblies, while for RNS-2 assemblies a complete release was visible. ${ }^{[53]}$ These results indicated that addition of RNF had enhanced the stability of assemblies but did not affect the gene release after reaching reductive conditions in vivo. Meanwhile, the size changes of RNF, RLS, and RNS-2/gene complexes in serum-containing medium were detected, showing mild increasement to $\approx 350 \mathrm{~nm}$ with zeta potential reduction (Figure S10C,D, Supporting Information), 

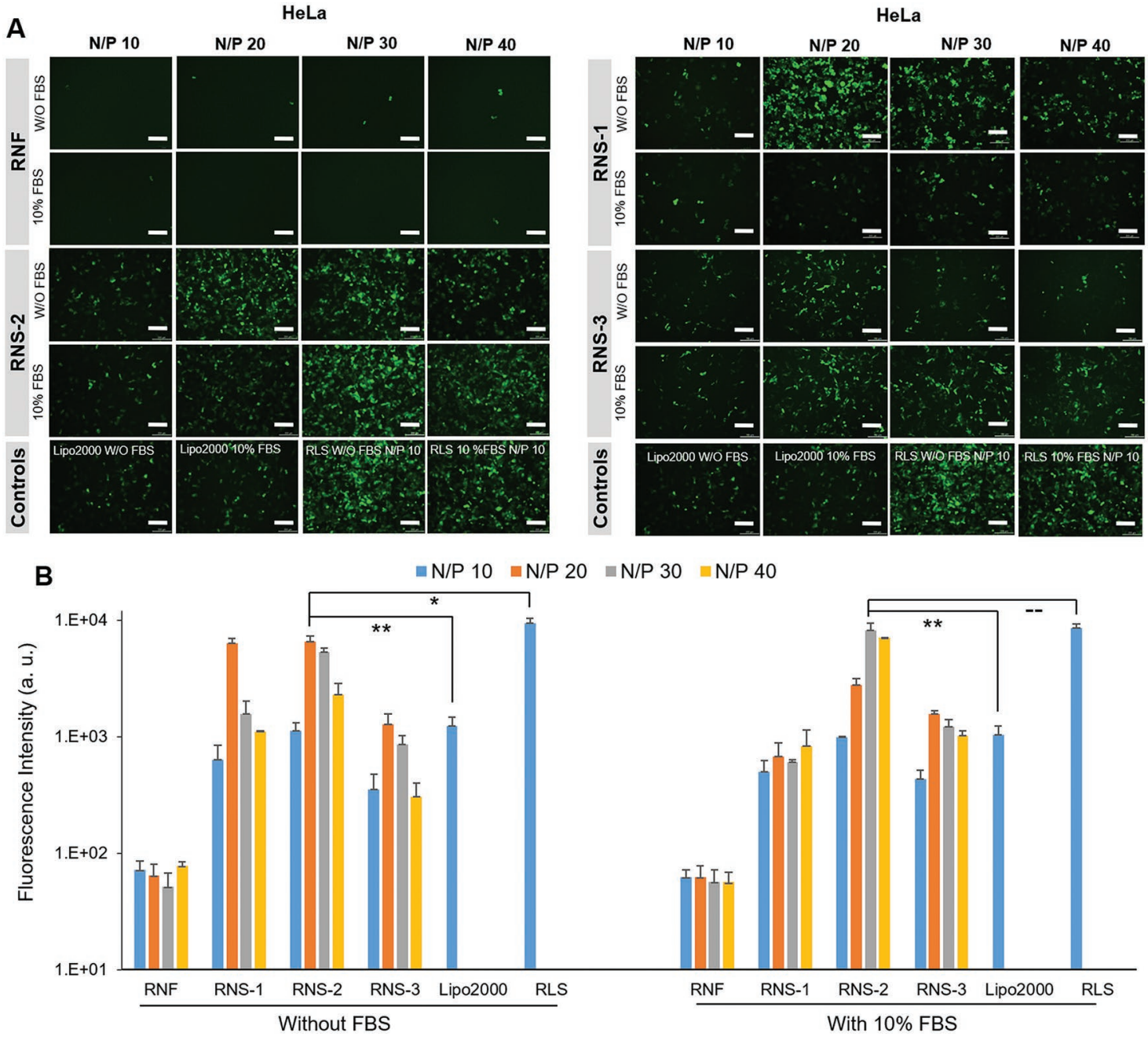

Figure 4. A) In vitro gene transfection effects on HeLa cells under the condition of culture medium without FBS or with $10 \%$ FBS. pEGFP plasmid DNA were condensed by RNF, RNS-1, RNS-2, and RNS-3 assemblies at different N/P ratios (N/P = 10, 20, 30, and 40). Lipofectamine 2000 and RLS assemblies were used as control groups. The N/P ratio of RLS/DNA complexes were 10. The scale bar was $200 \mu \mathrm{m}$. B) The semi-quantitative evaluation

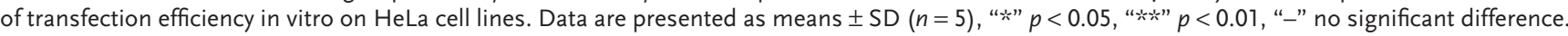

vdue to adsorption of negatively charged proteins and formation of protein corona on the surface of the particles.

\subsection{In Vitro Cytotoxicity Assay and Transfection Efficiency}

Cytotoxicity of carriers limits the applicability in drug or gene delivery. Thus, cell counter kit-8 (CCK-8) assay was used to evaluate the biocompatibility of various assemblies against HeLa, NIH3T3, and L929 cells (Figure S11, Supporting Information), respectively. According to the assembly concentration of 20-80 $\mu \mathrm{g} \mathrm{mL}^{-1}$ for in vitro gene transfection, the concentration range was set between 10 and $100 \mu \mathrm{g} \mathrm{mL} \mathrm{m}^{-1}$. It was demonstrated that all assemblies including RNF, RNS-1, RNS-2, and RNS-3 did not alter cell viability in the applied concentration range.

pEGFP as a plasmid for enhanced green florescent protein expression was employed as model gene to assess the transfection efficiency on Hela, HepG2, breast cancer cell line MCF-7, and B16 cell lines (Figure 4 and Figure S12, Supporting
Information). RNS-2 assemblies at the optimal N/P ratio have similar efficiency as RLS, which showed much more bright green fluorescence than the commercial Lipofectamine 2000 and other formulations (RNS-1 and RNS-3) on all cell lines with or without serum (Figure 4A and Figure S12A,C,D, Supporting Information). The differences between individual systems are more pronounced in the semi-quantitative analysis of gene transfer (Figure 4B and Figure S12B, Supporting Information). Under the serum-free conditions, HeLa cells transfected by RNS-2 complexes $(\mathrm{N} / \mathrm{P}$ ratio $=20)$ showed the best protein expression, reaching up to 5.3-fold higher than that transfected by Lipofectamine $2000(* * p<0.01)$. While the superiority was enhanced to sevenfold higher transfection for RNS-2 group at N/P ratio of $30(* * p<0.01)$ in $10 \%$ FBS, which was even better than that under serum-free conditions. Compared with other RNS groups, RNS-2 (N/P = 30) displayed approximately tenfold and fivefold higher transfection efficiency than RNS-1 and RNS-3 (at the optimal N/P ratio) under serum-containing conditions, respectively. Previous reports have found that rigid 
linkages could promote tighter and more stable formation and offer sequent benefit for gene condensation. ${ }^{[54]}$ That might illustrate the obviously decreased green fluorescent protein (GFP) expression by RNS-1 gene complexes from medium without serum to $10 \%$ serum condition. However, on the other hand, a tight condensation in the RNF assemblies would prevent penetration of reductive molecules (Figure 3), and the excessive rigidity of carriers (RNS-3) would decrease interaction with cell membrane, hinder endocytosis, obstruct gene release, and finally decrease transfection. ${ }^{[55]}$ Overall, the RNS-2 assemblies exhibited the best gene transfection effect especially in cell culture medium with $10 \%$ FBS.

\subsection{In Vitro Imaging for Disintegration of Assemblies}

In order to trace cellular uptake behavior and study fluorescence recovery inside the tumor cells, fluorescence imaging was carried out on HeLa and HepG2 cells by confocal laser scanning microscope (CLSM) with Hoechst33342 labeled nucleus, Cy3 labeled gene, and NIR channel for recovered indocyanine green observation (Figure 5A,B). At $2 \mathrm{~h}$, some green fluorescence from $\mathrm{Cy} 3$ channel and almost no NIR fluorescence could be detected inside cells, suggesting the successful cellular uptake and ACQ effect for intact carrier systems. With time ongoing, the fluorescent signal of Cy3 became stronger, indicating more and more gene complexes entering into the living cells, ensuring efficient internalization of RNS-2/DNA complexes. Meanwhile, the signal of NIR fluorescence from RNS-2 was also detectable and enhanced from 4 to $8 \mathrm{~h}$, owing to the fast cleavage of disulfide bonds and disintegration of assemblies. As shown in the initial 4-6 h images, orange fluorescent spots obviously appeared in the merged channel, as a result of an overlay of Cy3-labeled pGL3 (green) and nearinfrared fluorescence from cleaved indocyanine green analogs (red). Subsequently, at $8 \mathrm{~h}$, some of the pattern turned red and accumulated around the nuclear periphery, due to the proximity of the nucleus by endosome migration and successful
A

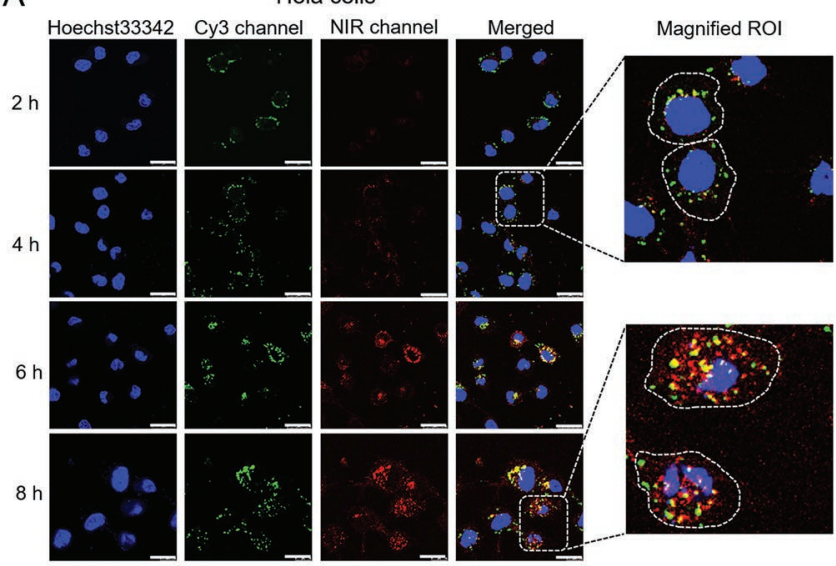

C
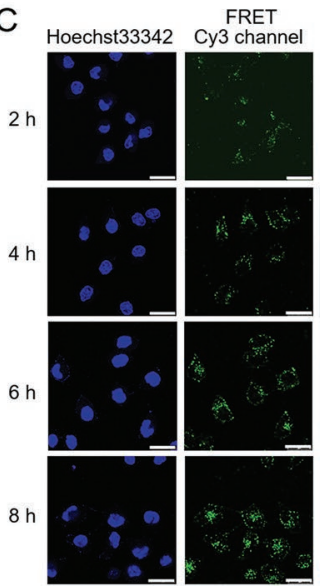

Hela cells
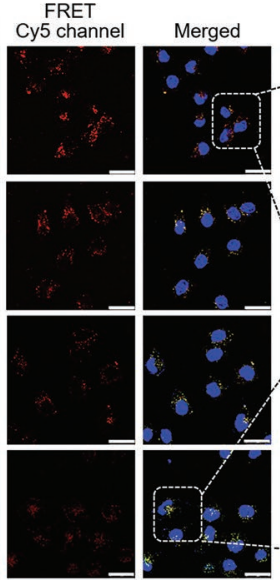

Magnified ROI
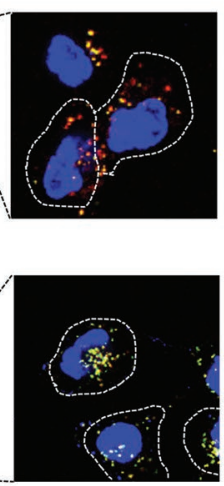

B
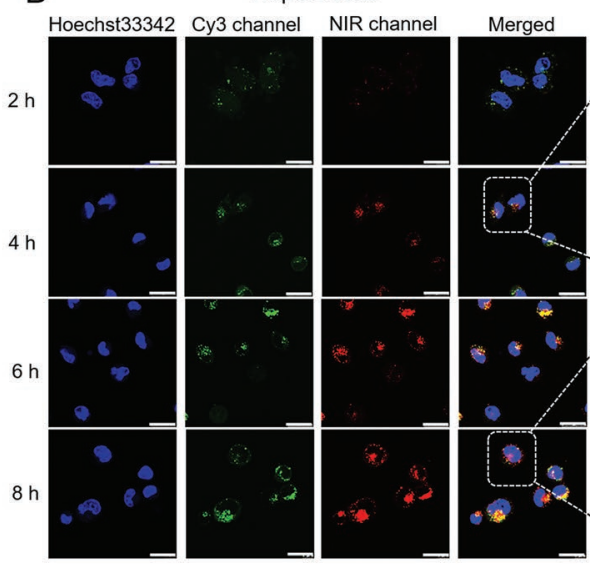

Magnified ROI

D

$E$
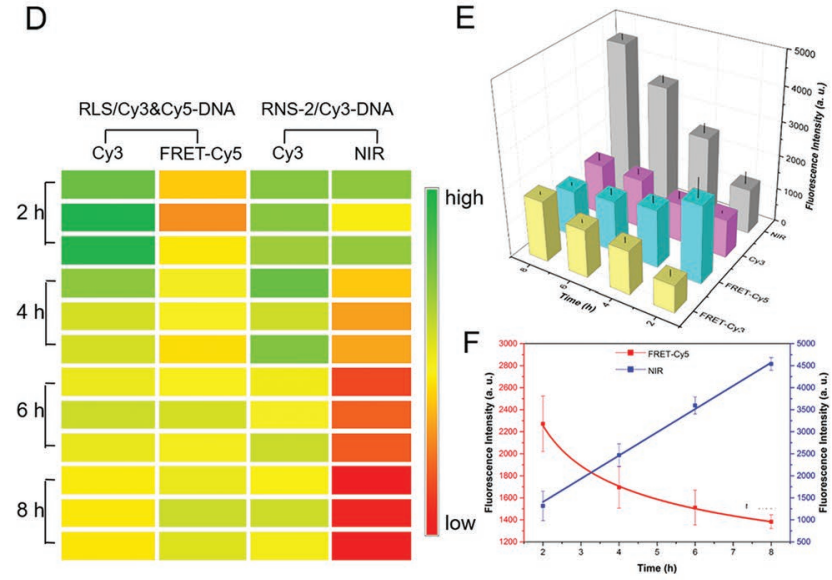

Figure 5. In vitro imaging with different fluorescent labeling by confocal laser scanning microscope (CLSM). Incubation of RNS-2 assemblies with Cy3-labeled plasmid DNA (N/P = 30) on A) HeLa and B) HepG2 cells for 2-8 h. Green: fluorescent signal of Cy3. Red: fluorescent signal of NIR. Blue: fluorescent signal of Hoechst33342 stained for nucleus. C) HeLa cells incubated with RLS/Cy3 and Cy5-DNA (N/P = 10) for 2-8 h. Cy3 and Cy5 were used as donor and acceptor of fluorescence resonance energy transfer (FRET) effect. Green: fluorescent signal of Cy3 (FRET donor Cy3). Red: FRETmediated Cy5 fluorescent signal. Blue: signal of Hoechst33342 for cell nucleuses staining. The scale bar was $25 \mu \mathrm{m}$. Analysis of correlation between various fluorescent signals with the dynamic process of gene complexes disintegration/gene release by D) heatmap, E) histogram, and F) fitted curve analysis. Data are presented as means \pm SD $(n=5)$. 
gene release from the compression situation. On the contrary, fluorescein isothiocyanate (FITC) labeled PEI together with Cy3 labeled gene complexes constantly showed well colocalization of Cy3 and FITC signals due to tight condensation of DNA by PEI during the time period (Figure S13A, Supporting Information). It was more intuitively that the semi-quantified $R$ (Mander's overlap coefficient) value was gradually decreased over time, inflecting the colocalization of DNA and RNS-2 carriers more directly (Figure S13B,C, Supporting Information) (from 0.94 to 0.59 on Hela cells and 0.96 to 0.54 on HepG2 cells, $* * p<0.01)$.

In previous studies, we exploited Cy3 and CY5 double labeled DNA as a donor/acceptor with FRET effect to investigate the gene release process inside cells. ${ }^{[15,18]}$ The dynamic change in fluorescent signals (FRET Cy3 and FRET Cy5) could timely indicate the compression or decompaction status of gene, while the only drawback was the intensity of FRET Cy5 existed negative relationship with the amount of gene release. Herein, we speculated the carriers with ACQ effect and reductive triggered fluorescent recovery can provide a better detectable and visual strategy for the bioimaging. RLS assemblies (without indocyanine green modification) and PEI were used as contrasts for condensation of $\mathrm{Cy} 3$ and $\mathrm{Cy} 5$ labeled gene $(\mathrm{N} / \mathrm{P}=10)$, respectively (Figure 5C and Figure S13E, Supporting Information). The fluorescence of $\mathrm{Cy} 3$ was pseudo-colored green to distinguish it from the red fluorescence of FRET-mediated Cy5. In the RLS/Cy3 and Cy5 double-labeled DNA group (Figure 5C), we could observe the strong signal of Cy5 and very weak signal of Cy3 at the beginning ( $2 \mathrm{~h}$ ), due to the close distance of donor and acceptor fluorescence in condensed DNA. As time went on, DNA was gradually released from the complexes, the signal of $\mathrm{Cy} 3$ became stronger and that of $\mathrm{Cy} 5$ get dimmer, attributing to the weakened FRET effect. The semi-quantified $R$ value for merged images of $\mathrm{Cy} 3$ and $\mathrm{Cy} 5$ always kept constant (Figure S13D, Supporting Information). On the other hand, strong FRET-mediated Cy5 signal could be observed for a long time in the PEI group, which demonstrated the tight condensation status of DNA (Figure S13E, Supporting Information). The comparison of the fluorescent signal changes from confocal laser scanning microscope imaging (Figure 5A,C) was visualized in a heatmap (Figure 5D) and histogram analysis (Figure 5E). Heatmaps represented the level of fluorescent intensity, where green and red color represented the relative fold change of fluorescent intensity decrease and increase, respectively. We could clearly see that the signal intensity of NIR, Cy3, and FRET-Cy3 dyes were enhanced with time, while the signal of FRET-Cy5 reduced gradually. It was exciting that the recovered intensity of NIR dye was the strongest among them with $\approx 4.2$-fold higher increasement than at the beginning, while the signals of $\mathrm{Cy} 3$ and FRET-Cy3 only showed about $\approx 1$.5-fold enhancement. On the other hand, when the change of the FRET-Cy5 signal exhibited a negative correlation with time, the relationship between NIR dye and time was positive (Figure 5F). The fitted curve analysis of $\mathrm{Cy} 3$ and FRET-Cy3 were presented in Figure S14A-D in the Supporting Information. In conclusion, the fluorescent recovery of indocyanine green analogs could appropriately monitor disintegration of assemblies, trace gene release, and allow for a much visualization of the dynamic process compared with Cy3 and Cy5 double labeled FRET indicator.

\subsection{In Vivo Imaging and Gene Transfection}

The in vivo imaging of the RNS-2 assemblies without DNA was evaluated before (Figure S15A, Supporting Information) and after intratumoral injection $(0.5-24 \mathrm{~h}$ ) (Figure S15B-E, Supporting Information). As expected, the assemblies in aqueous solution did not show fluorescent signal, while addition of methanol led to a disassembly of aggregates and strong detectable fluorescence (Figure S15A, Supporting Information). In the animal experiment, the region of interest was set at tumor based on the bright field. It was observed that the fluorescence intensity was gradually enhanced with time (Figure S15B, Supporting Information). At the beginning (before $1 \mathrm{~h}$ ), there was weak fluorescence signal at tumor site, while it reached the highest intensity at $9 \mathrm{~h}$ and maintained strong until $24 \mathrm{~h}$ postinjection (Figure S15B,D, Supporting Information). During the whole imaging process, other tissues apart for tumor showed hardly any signal, which was additionally confirmed by the ex vivo imaging of the isolated tissues at $24 \mathrm{~h}$ end point of the study (Figure S15C,E, Supporting Information).

Above results have underlined the desired fluorescence "Off" and "On" property of RNS-2 in vivo and arouse further studies on the "signal to noise" (STN) for the gene delivery imaging. It was clearly visible that signal from Cy5 channel was relatively dispersed, while that from the NIR channel was more localized at tumor (Figure 6A). Considering the similar metabolic pathway of $\mathrm{Cy} 5$ and indocyanine green derivatives, ${ }^{[56,57]}$ the disseminated signal from Cy5 channel that out of the tumor site may result from degraded DNA-Cy5 fragments. A semi-quantificative comparing analysis of the signal from tumor to total signal from the whole body could give a preliminary assessment about the "signal to noise" of Cy5 and ICG analogs, respectively (Figure 6B). The STN values of NIR always remained very high (0.85-0.93) from 3 to $24 \mathrm{~h}$ after injection, which means almost no signal was detected outside the tumor. While the STN value of Cy5 was much lower (0.13-0.30), implying serious interference with background fluorescence. From the isolated tissues imaging at $24 \mathrm{~h}$, obvious strong signal was detected from Cy5 channel in normal tissues (heart, liver, spleen, lung, and kidney), but relatively weak from the NIR channel (Figure 6C). Similarly, in the semi-quantificative assessment, tumor showed up to 200fold higher fluorescent intensity than other tissues from NIR channel, while only 30-fold was obtained from Cy5 channel (Figure 6D,E).

Such high signal-to-noise radio has confirmed the precision advantages of the developed indocyanine green analog based gene carrier, the further accuracy for the gene expression location remained to be addressed. Therefore, pEGFP (Figure 7A-C) or Cy3 labeled pGL3 (Figure 7D-F) was condensed by RNS-2 assemblies at $\mathrm{N} / \mathrm{P}=30$ and the mixed gene complexes were intratumorally injected, respectively. Isolated tissues from the sacrificed mice were observed by Cambridge Research \& Instrumentation (CRI) Maestro Imaging System (Figure 7A,D) and semi-quantitative analysis was performed $48 \mathrm{~h}$ later (Figure 7C,E). Considerable green fluorescence signal from the GFP channel could be observed in the isolated tumor (Figure 7A), indicating pronounced protein expression and 
B

A
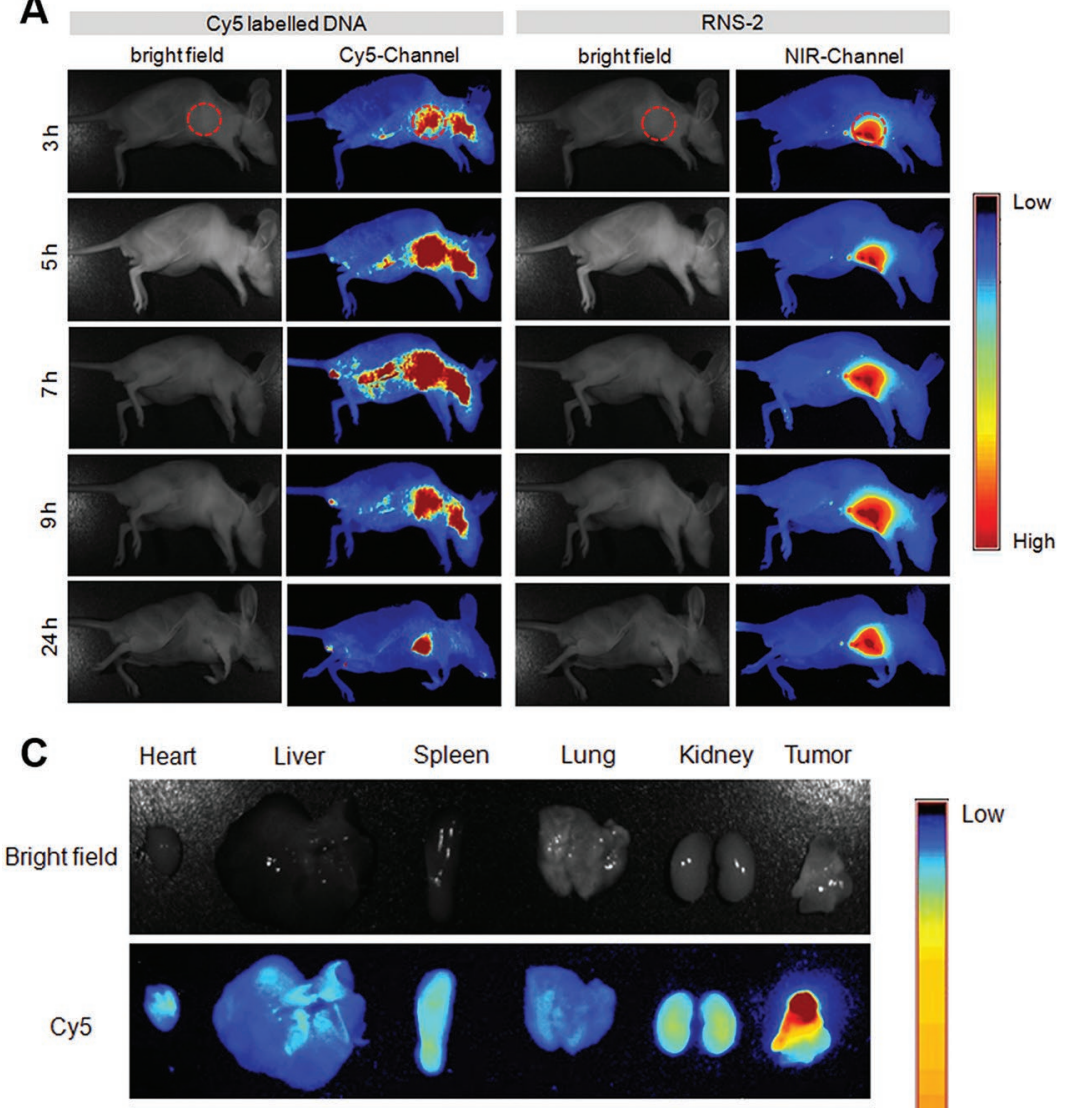

NIR

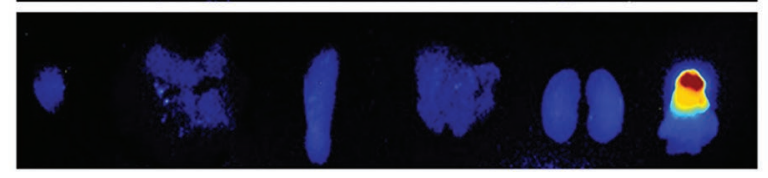

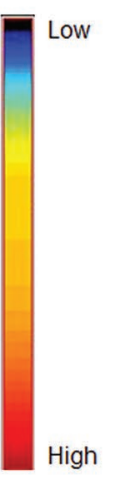

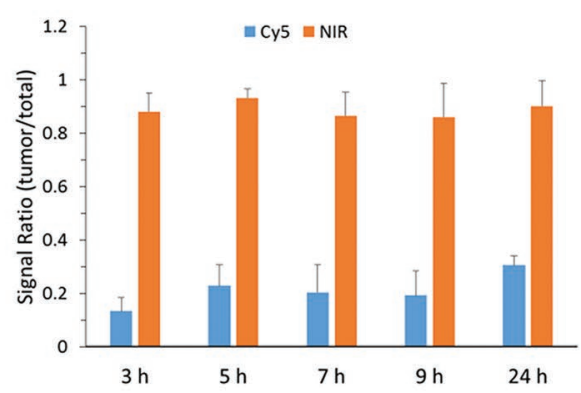

D

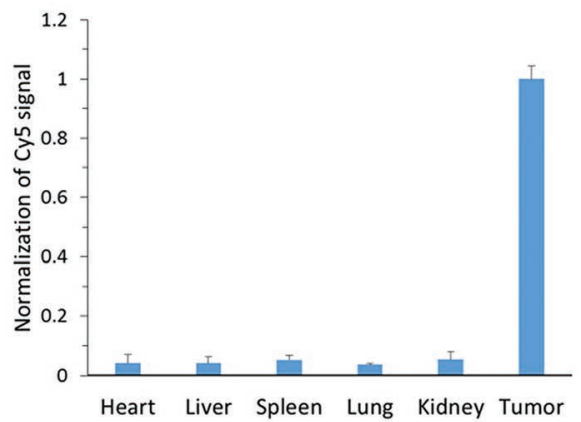

E

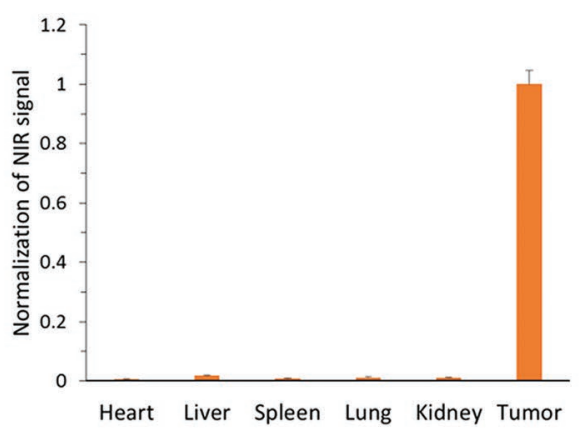

Figure 6. Fluorescence imaging for the RNS-2/Cy5-DNA complexes (N/P = 30) through intratumoral injection. A) In vivo imaging detected from Cy5 and NIR channel at different time after injection, respectively. The tumor site was marked by red circle. B) The semi-quantificative analysis of signal to noise of Cy5 and ICG analogs by comparing the Cy5 and NIR signals from tumor with total signal from the whole body, respectively. C) The $24 \mathrm{~h}$ imaging of isolated tissues detected from Cy5 and NIR channel after injection (heart, liver, spleen, lung, kidney, and tumor), respectively. The semiquantitative analysis for the fluorescence intensity of D) Cy5 signal and E) NIR signal in isolated tissues. Data are presented as means \pm SD ( $n=5)$.

efficient gene transfection by RNS-2 complexes. Other tissues (including heart, liver, spleen, lung, and kidney) showed hardly detectable signals due to poor gene expression. Excitingly, fluorescence signal from NIR channel corresponded well to the result from GFP channel, providing accurate location for gene expression. On the other hand, when we observed the RNS-2/Cy3-DNA complexes $(\mathrm{N} / \mathrm{P}=30)$ group, not only tumor but also other organs (especially liver, lung and kidney) showed obvious signals from channel Cy3 (Figure 7D,F). That means Cy3-labeled DNA probably provide a false positive indication for the gene expressed site. The frozen sections of isolated organs also showed the same results (Figure 7B,E). Previous studies have found direct gene labeling could reduce the transfection by altering the conformation of nuclear acid, ${ }^{[58]}$ while physical encapsulation or peripheral residues bonding of probe to the nanocarrier may be suffered from leaking. ${ }^{[30]}$ Our designed RNF molecules, in which the fluorescence dye was used as skeleton structure of carriers has proved to be a more accurate indication strategy.

\subsection{Biodistribution and Biocompatibility Assays}

In order to assess the biodistribution/premature leakage of assemblies in vivo, the complexes of RNS-2 assemblies condensing $15 \mu \mathrm{g}$ Cy5-labeled DNA with N/P $=30$ were intravenously injected into mice. From 5 to $24 \mathrm{~h}$ after injection, Cy5 signals were dispersed and could observed in liver, lung, spleen, and kidney, while NIR signal mainly concentrated on the liver, indicating that the ICG-based assemblies did not leakage prematurely (Figure S16, Supporting Information).

The in vivo biocompatibility/biosafety was evaluated by acute toxicity test via intravenously injecting high dose of RNS-2/ DNA complexes. All indicators in both hematological analysis (Table S1, Supporting Information) and serum biochemistry analysis (Table S2, Supporting Information) were in the normal range, showing no obvious difference with saline group. In addition, obvious pathological changes could not detectable in the major organs by hematoxylin and eosin (H\&E) staining (Figure S17, Supporting Information). 
A

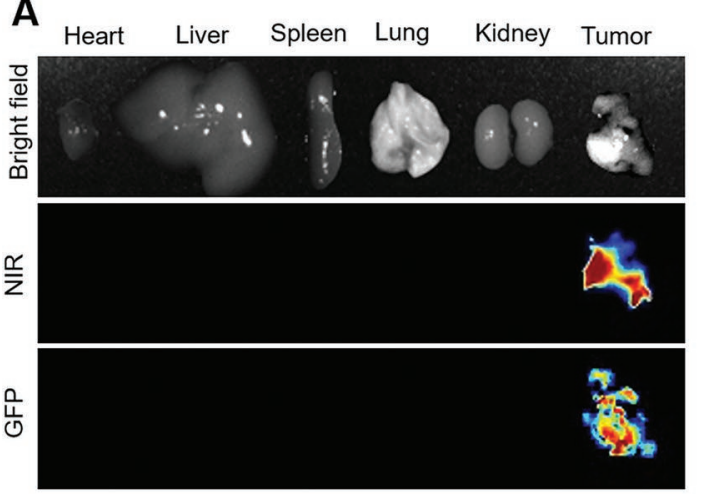

D
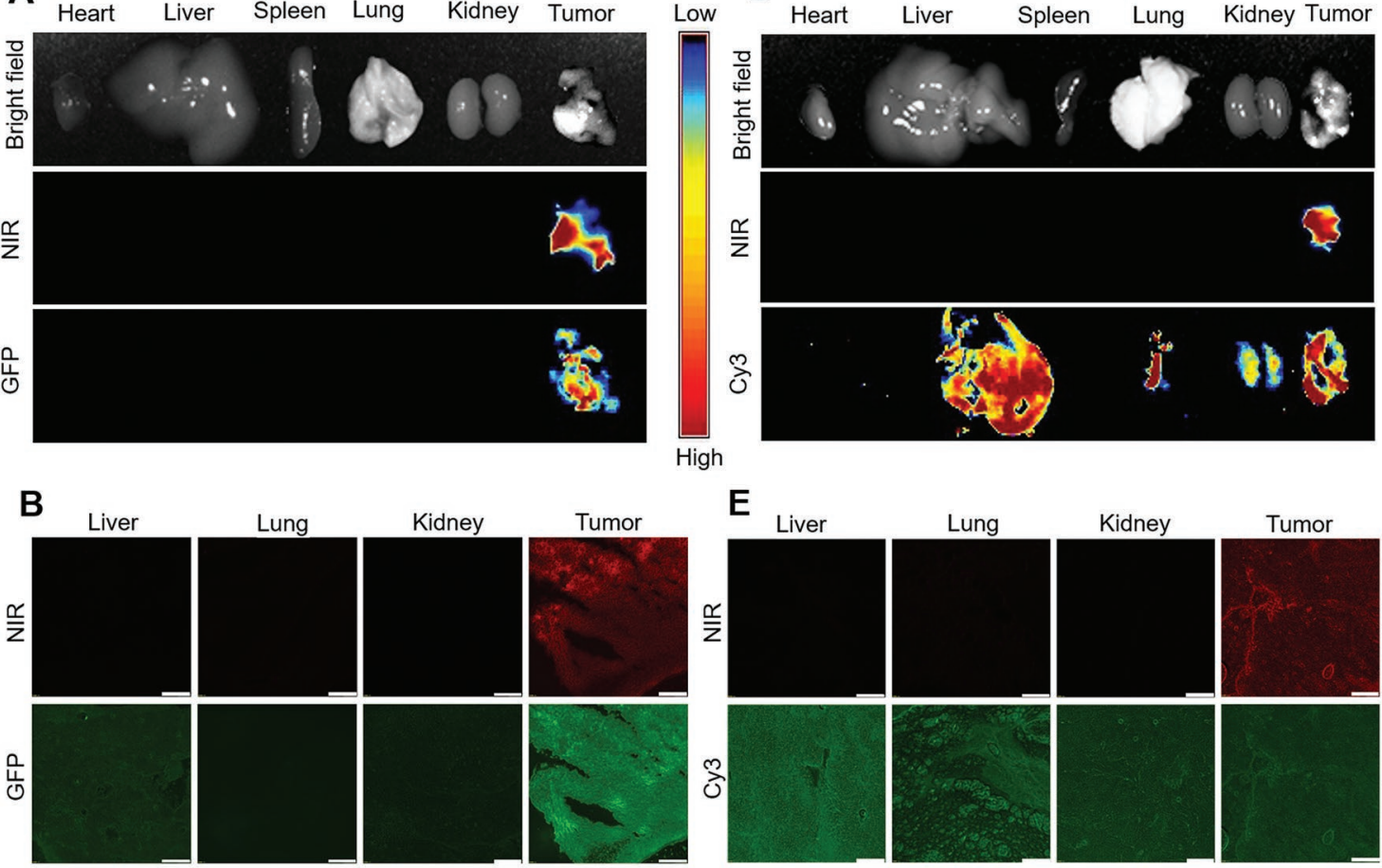

$E$

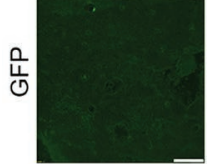

C

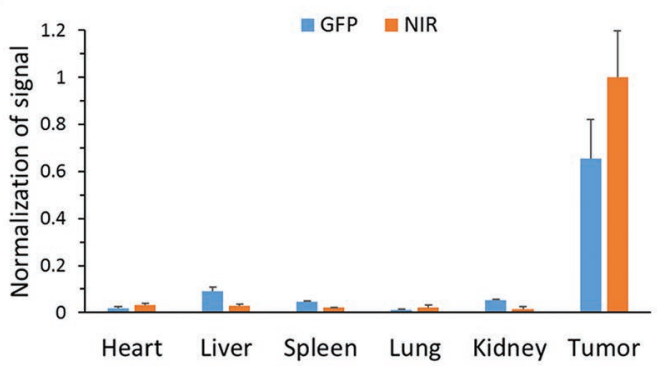

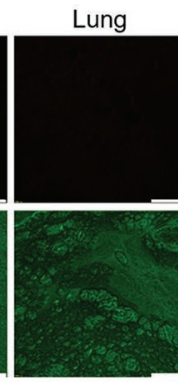
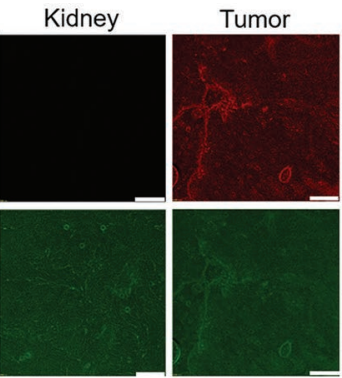

$\mathbf{F}$

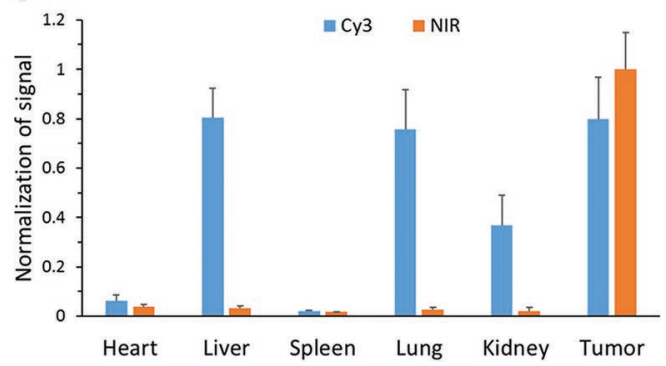

Figure 7. In vivo green fluorescent protein expression and fluorescent probe signals at $48 \mathrm{~h}$ after intratumoral injection of A-C) RNS-2/pEGFP or $D-E)$ RNS-2/Cy3-labeled pGL3, respectively $(N / P=30)$. A,D) The fluorescence imaging of isolated tissues from different channels (GFP, NIR, and Cy3 channels) observed by CRI Maestro Imaging System, respectively. B,E) Frozen section imaging of normal tissues and tumor from GFP, NIR, and Cy3 channels, respectively (observed by CLSM). The scale bar was $200 \mu \mathrm{m}$. C,F) Semi-quantitative analysis of the fluorescence intensity of isolated tissues, respectively. Data are presented as means \pm SD $(n=5)$.

\section{Conclusion}

In this study, we have introduced a novel molecular design concept for theranostic gene delivery system. We report the synthesis and optical properties of a novel amphiphile named RNF, which rationally integrated indocyanine green analogs and arginine-rich dendritic polypeptides in a single defined molecule. By assembly with other lipopeptides at optimal conditions, a theranostic system (RNS-2) for gene delivery and fluorescence imaging can be constructed. The obtained gene delivery system possessed nanoscaled size around $106 \mathrm{~nm}$, ellipsoidal shape, and zeta potential of $+20 \mathrm{mV}$. The RNS-2/pDNA complexes exhibited significant variation in size distribution and DNA liberation once disassembling in the presence of reducing agents as visualized by the dynamic laser scanning and gel electrophoresis assay. Meanwhile, the fluorescent signal of the RNS-2 assemblies exhibited activable "OFF" and "ON" properties, which being quenched by ACQ effect in the assembly state and light up in the presence of GSH. In vitro transfection confirmed that RNS-2 gene complexes achieved excellent gene transfection efficacy in different cell lines (HeLa, HepG2, MCF7, and B16 cells) at noncytotoxic concentration. Observation from confocal laser scanning microscopy showed that the fluorescent recovery could appropriately indicate disintegration of assemblies and gene release, which enable tracing of the dynamic processes of gene delivery. In vivo imaging showed that RNS-2 assemblies lead to a highly localized signal with enhanced signal-to-noise ratio compared to conventional FRET pairs. Therefore, not only efficient gene transfer in vivo has been confirmed but also imaging accuracy for gene expression location could be ensured. Collectively, RNS-2 assemblies could be a promising theranostic system for efficient local gene delivery and precise real-time imaging. 


\section{Experimental Section}

Materials: All chemicals and solvents were reagent grade. 2,3,3-Trimethylindolenine, 1-bromopropane, cyclohexanone, sodium acetate anhydrous, phloretic acid, di-tert-butyl dicarbonate, L-lysine methyl ester dihydrochloride, and TBTU were purchased from Aladdin (Shanghai, China). Cystamine dihydrochloride, anhydrous $N, N$-dimethylformamide (DMF), and anhydrous dimethyl sulfoxide were purchased from $/ \& K$ Scientific Ltd. (Beijing, China). Acetic anhydride and 1-bromohexadecane were purchased from Adamas-beta (Shanghai, China). Trifluoroacetic acid (TFA) and DIEA were purchased from Astabiochem Ltd. (Chengdu, China). Boc-Arg(Pbf)-OH was purchased from GL Biochem Ltd. (Shanghai, China). CCK-8 was purchased from Dojindo Laboratories (Kumamoto, Japan). The nucleic acid labeling kit Label IT Cy3 and Cy5 were obtained from Mirus. Hoechst 33342 and FITC were purchased from Solarbio S\&T Co. (Beijing, China). L-Glutathione (GSH) was purchased from Beyotime (Nantong, China). Dulbecco's modified Eagle's medium (DMEM) with high glucose, penicillin, streptomycin, and FBS were purchased from Hyclone (USA). Lipofectamine 2000 and SYBR Safe DNA Gel Stain were obtained from Thermofisher (USA). All reagents were purchased from commercial suppliers and used without further purification unless other stated. Deionized water and triple distilled water were used throughout the experiments. NMR spectra were recorded at ${ }^{7} \mathrm{H}(400 \mathrm{MHz})$ on a Bruker instrument. Chemical shifts ( $\delta$ values) and coupling constants $(U$ values) are given in ppm and hertz, respectively, using solvents as the internal standard. Mass spectral analyses were performed on an ABI API 3200 (electrospray ionization-Triple Quadruple).

Synthesis of Oleic Acid-Containing (RLS) and Near-Infrared (NIR) Fluorescence Dye-Containing (RNF) Amphipathic Dendritic Lipopeptide: The oleic acid-containing amphipathic dendrimer (RLS) was synthesized according to the previous work, ${ }^{[15,38,59]}$ and the NIR fluorescence dyecontaining amphipathic dendrimer (RNF) was prepared according to the classic method with some modification. Briefly, 2,3,3-trimethylindolenine $(5 \mathrm{~g}, 30 \mathrm{mmol})$ and 1-bromohexadecane $(14.3 \mathrm{~g}, 47 \mathrm{mmol})$ were dissolved in toluene $(100 \mathrm{~mL})$. And then the reaction was heated to $130{ }^{\circ} \mathrm{C}$ and stirred for $72 \mathrm{~h}$ under nitrogen atmosphere. The solvent was concentrated under reduced pressure to give the crude product. The crude product was purified by silica column chromatography to yield compound 1 (10.77 g, $37 \%)$. The solution of phosphorus oxychloride $(30.6 \mathrm{~g}, 200 \mathrm{mmol})$ in $8 \mathrm{~mL}$ dichloromethane was slowly added into anhydrous DMF $(20 \mathrm{~mL}$, $14.6 \mathrm{~g}, 200 \mathrm{mmol}$ ) with stirring in ice-water bath. After that, cyclohexanone $(5 \mathrm{~g}, 50 \mathrm{mmol})$ was added into the solution and the mixture was refluxed overnight under nitrogen atmosphere. The mixture was cooled and slowly poured into $100 \mathrm{~mL}$ ice-cold water. The solution was kept in $-20^{\circ} \mathrm{C}$ to yield precipitation (compound 2, yellow solid with $5.86 \mathrm{~g}, 68 \%$ yield). Next, a mixture of compound 1 ( $3 \mathrm{~g}, 6.4 \mathrm{mmol})$, compound 2 ( $0.44 \mathrm{~g}, 2.6 \mathrm{mmol})$, and sodium acetate anhydrous $(0.79 \mathrm{~g}, 7.7 \mathrm{mmol})$ were dissolved in $20 \mathrm{~mL}$ acetic anhydride. The reaction was stirred overnight at $65^{\circ} \mathrm{C}$ under nitrogen atmosphere in dark. After that, the mixture was dissolved in $300 \mathrm{~mL}$ dichloromethane and washed by saturated brine $(3 \times 50 \mathrm{~mL})$. The organic phase was dried with anhydrous magnesium sulfate and concentrated in vacuum to give crude product. The crude product was purified by silica column chromatography to yield compound 3 as green solid $(1.87 \mathrm{~g}, 74 \%)$. ${ }^{1} \mathrm{H}$ NMR $\left(400 \mathrm{MHz} \mathrm{CDCl}_{3}\right), \delta$ (ppm) (Figure S1, Supporting Information): $8.36(\mathrm{~d}, J=12.0 \mathrm{~Hz}, 2 \mathrm{H}), 7.38(\mathrm{~d}, J=7.5 \mathrm{~Hz}, 2 \mathrm{H}), 7.26(\mathrm{~d}, J=7.6 \mathrm{~Hz}, 2 \mathrm{H})$, $7.18(\mathrm{~d}, J=7.9 \mathrm{~Hz}, 2 \mathrm{H}), 6.29(\mathrm{~d}, J=16.0 \mathrm{~Hz}, 2 \mathrm{H}), 4.21(\mathrm{t}, J=6.0 \mathrm{~Hz}, 4 \mathrm{H})$, $2.74(\mathrm{t}, J=6.0 \mathrm{~Hz}, 4 \mathrm{H}), 1.99(\mathrm{~m}, 2 \mathrm{H}), 1.72(\mathrm{~s}, 12 \mathrm{H}), 1.25(\mathrm{~s}, 56 \mathrm{H}), 0.87(\mathrm{t}$, $J=6.0 \mathrm{~Hz}, 6 \mathrm{H}$ ). Matrix-assisted laser desorption/ionization-time of flightmass spectrum (MALDI-TOF-MS): calcd. For $\mathrm{C}_{62} \mathrm{H}_{96} \mathrm{ClN}_{2}{ }^{+} \mathrm{m} / \mathrm{z} 903.73$ [M]; found $m / z$ 903.78 [M].

Compound 3 (1.4 g, $1.42 \mathrm{mmol})$ was dissolved in $20 \mathrm{~mL}$ dimethylsulfoxide and the phloretic acid sodium salt $(1.5 \mathrm{~g}, 7.14 \mathrm{mmol})$ was added. And then the reaction was heated to $65{ }^{\circ} \mathrm{C}$ for $5 \mathrm{~h}$ in dark. When it was cooled to room temperature, $100 \mathrm{~mL}$ dichloromethane was added. The mixture was washed by saturated brine and the organic phase was concentrated in vacuum. The precipitate was redissolved in methanol and the $\mathrm{pH}$ was adjusted to 2 with $1 \mathrm{~m}$ hydrochloric acid. $100 \mathrm{~mL}$ dichloromethane was added and the mixed solution was washed twice by saturated brine. Organic phase was combined and dried with anhydrous magnesium sulfate and concentrated by rotary evaporation. The obtained crude product was purified by silica column chromatography to obtain compound 4 as green solid $(0.4 \mathrm{~g}, 27 \%)$. Compound 5 ( $0.14 \mathrm{~g}, 0.54 \mathrm{mmol})$ was prepared as the previous work ${ }^{15,38]}$ and compound $4(0.4 \mathrm{~g}, 0.36 \mathrm{mmol}$ ) were dissolved in $10 \mathrm{~mL}$ anhydrous DMF. Appropriate amount of TBTU $(0.23 \mathrm{~g}, 0.72 \mathrm{mmol})$ and DIEA $(0.09 \mathrm{~g}, 0.72 \mathrm{mmol})$ were added into the above solution. The mixture was stirred at $30^{\circ} \mathrm{C}$ for $48 \mathrm{~h}$ under nitrogen atmosphere in dark for complete reaction. After that, DMF was removed in vacuum, and other $100 \mathrm{~mL}$ dichloromethane was added for redissolution and successively washed by saturated sodium bicarbonate, sodium dihydrogen phosphate, and brine, respectively. The combined organic phase was dried with anhydrous magnesium sulfate and concentrated in vacuum. The crude product was purified by silica column chromatography to obtain compound 6 as green solid $(0.3 \mathrm{~g}, 63 \%)$. Compound 6 ( $0.3 \mathrm{~g}$, $0.22 \mathrm{mmol}$ ) was dissolved in $10 \mathrm{~mL}$ dichloromethane together with the same volume of trifluoroacetic acid, stirring in ice-water bath. And then the mixture was stirred at $30^{\circ} \mathrm{C}$ for $5 \mathrm{~h}$ in dark. The redundant solvent was removed in vacuum. The product was precipitated by diethyl ether and concentrated by centrifugation. The residual diethyl ether was removed to obtain compound 7 as green solid $(0.51 \mathrm{~g}, 91 \%) .{ }^{1} \mathrm{H}$ NMR $\left(400 \mathrm{MHz}, \mathrm{CDCl}_{3}\right), \delta(\mathrm{ppm}): 7.93(\mathrm{~d}, J=12.0 \mathrm{~Hz}, 2 \mathrm{H}), 7.34$ (d, $J=7.6 \mathrm{~Hz}, 2 \mathrm{H}), 7.32(\mathrm{~d}, J=8.3 \mathrm{~Hz}, 2 \mathrm{H}), 7.22(\mathrm{~d}, J=7.6 \mathrm{~Hz}, 2 \mathrm{H}), 7.03$ $(\mathrm{d}, J=7.9 \mathrm{~Hz}, 2 \mathrm{H}), 6.92(\mathrm{~d}, J=8.6 \mathrm{~Hz}, 2 \mathrm{H}), 5.94(\mathrm{~d}, J=14.2 \mathrm{~Hz}, 2 \mathrm{H})$, $3.93(\mathrm{t}, J=6.0 \mathrm{~Hz}, 4 \mathrm{H}), 3.45(\mathrm{~m}, 2 \mathrm{H}), 3.27(\mathrm{~m}, 2 \mathrm{H}), 2.93(\mathrm{t}, J=6.0 \mathrm{~Hz}$, $4 \mathrm{H}), 2.65(\mathrm{~m}, 6 \mathrm{H}), 2.04(\mathrm{t}, J=4.0 \mathrm{~Hz}, 2 \mathrm{H}), 1.78(\mathrm{~m}, 2 \mathrm{H}), 1.33(\mathrm{~s}, 12 \mathrm{H})$, $1.25(\mathrm{~s}, 56 \mathrm{H}), 0.88(\mathrm{t}, J=6.0 \mathrm{~Hz}, 6 \mathrm{H})$. MS (MALDI-TOF-MS): calcd. For $\mathrm{C}_{75} \mathrm{H}_{115} \mathrm{~N}_{4} \mathrm{O}_{2} \mathrm{~S}_{2}{ }^{+} \mathrm{m} / \mathrm{z} 1167.85$ [M]; found $\mathrm{m} / \mathrm{z} 1167.88$ [M].

Compound $8(0.7 \mathrm{~g}, 0.6 \mathrm{mmol})$ prepared according to previous work $^{[15,38]}$ and compound $7(0.5 \mathrm{~g}, 0.4 \mathrm{mmol})$ were dissolved in $10 \mathrm{~mL}$ anhydrous DMF. Appropriate amount of TBTU $(0.26 \mathrm{~g}, 0.8 \mathrm{mmol})$ and DIEA $(0.1 \mathrm{~g}, 0.8 \mathrm{mmol})$ were added. The mixture was stirred at $30^{\circ} \mathrm{C}$ for $48 \mathrm{~h}$ under nitrogen atmosphere in dark. The residual DMF was removed in vacuum and then $100 \mathrm{~mL}$ of dichloromethane was added. The mixture was washed with aqueous solution as mentioned above. The organic phase was dried with anhydrous magnesium sulfate and concentrated by rotary evaporation. The crude product was purified by silica column chromatography to obtain compound 9 as green solid $(0.67 \mathrm{~g}, 70 \%)$. Then compound $9(0.17 \mathrm{~g}, 0.07 \mathrm{mmol})$ was removed the protective groups of amino to obtain compound 10 as green solid $(0.095 \mathrm{~g}, 79 \%)$. ${ }^{1} \mathrm{H}$ NMR (400 MHz, CD3OD), $\delta(\mathrm{ppm}): 8.03(\mathrm{~d}, J=16.0 \mathrm{~Hz}, 2 \mathrm{H}), 7.42$ $(\mathrm{d}, J=7.4 \mathrm{~Hz}, 2 \mathrm{H}), 7.38(\mathrm{~d}, J=8.0 \mathrm{~Hz}, 2 \mathrm{H}), 7.28(\mathrm{~d}, J=7.8 \mathrm{~Hz}, 2 \mathrm{H})$, $7.23(\mathrm{~d}, J=7.5 \mathrm{~Hz}, 2 \mathrm{H}), 7.07(\mathrm{~d}, J=8.2 \mathrm{~Hz}, 2 \mathrm{H}), 6.18(\mathrm{~d}, J=12.0 \mathrm{~Hz}$, $2 \mathrm{H}), 4.32(\mathrm{~m}, 1 \mathrm{H}), 4.12(\mathrm{t}, J=8.0 \mathrm{~Hz}, 4 \mathrm{H}), 3.50(\mathrm{~m}, 4 \mathrm{H}), 3.42(\mathrm{~m}, 2 \mathrm{H})$, $3.25(\mathrm{~m}, 6 \mathrm{H}), 2.87(\mathrm{t}, J=6.0 \mathrm{~Hz}, 4 \mathrm{H}), 2.75(\mathrm{~m}, 6 \mathrm{H}), 2.07(\mathrm{t}, J=6.0 \mathrm{~Hz}$, $2 \mathrm{H}), 1.82(\mathrm{~m}, 8 \mathrm{H}), 1.43(\mathrm{~m}, 6 \mathrm{H}), 1.36(\mathrm{~s}, 12 \mathrm{H}), 1.30(\mathrm{~s}, 58 \mathrm{H}), 0.90(\mathrm{t}$, $J=6.0 \mathrm{~Hz}, 6 \mathrm{H}$ ). MS (MALDI-TOF-MS): calcd. For $\mathrm{C}_{93} \mathrm{H}_{151} \mathrm{~N}_{14} \mathrm{O}_{5} \mathrm{~S}_{2}{ }^{+} \mathrm{m} / \mathrm{z}$ 1609.15 [M]; found $m / z 1609.34$ [M].

Self-Assembly and Characterization of Nanoparticles: The self-assembly nanoparticles RLS, RNF, RNS-1 (RLS/RNF $=1 / 1, \mathrm{~m} / \mathrm{m}$ ), RNS-2 (RLS/ $\mathrm{RNF}=2 / 1, \mathrm{~m} / \mathrm{m})$, and RNS-3 $(\mathrm{RLS} / \mathrm{RNF}=3 / 1, \mathrm{~m} / \mathrm{m})$ were prepared by injection method. Briefly, $1 \mathrm{mg}$ of sample in $100 \mu \mathrm{L}$ dimethylsulfoxide was dropped into $1 \mathrm{~mL}$ ultrapure water with rapid stirring. The assembly solution was obtained after $1 \mathrm{~h}$ and the absorption spectra were performed on a UV-vis spectrophotometer (HITACHI, U-2910, Japan) at room temperature in methanol. The excitation and emission spectra in methanol and water were detected by fluorescence spectrometer (HITACHI, F-7000, Japan), respectively. The size and zeta potential were detected by DLS with a Zetasizer Nano ZS (Malvern, Worcestershire, UK) at $25^{\circ} \mathrm{C}$, and the morphologies of every assemblies were observed by transmission electron microscopy (JEM-2100 Plus, JEOL, Japan).

Gene Condensation and Release: The assemblies were mixed with pDNA (200 ng) at various N/P ratios $(\mathrm{N} / \mathrm{P}=0,1,2,5,10,20)$ to form the gene complexes after $20 \mathrm{~min}$ incubation at room temperature. The gel electrophoresis assay was used to evaluate the gene condensation and release ability of assemblies under the condition of with or without $10 \times 10^{-3} \mathrm{M}$ glutathione. All samples were loaded into $1 \%$ agarose gel for electrophoresis $(85 \mathrm{~V}, 1 \mathrm{~h})$. The gels were stained with SYBR and visualized by the Molecular Imager ChemiDoc XRS+ (Bio-Rad, USA) 
In Vitro Cytotoxicity: The cytotoxicity of assemblies was tested by Cell Counting Kit-8 (CCK-8) assay. Briefly, HeLa, NIH3T, and L929 cells were seeded into 96 -well plates with a density of $1 \times 10^{4}$ per well and incubated for $24 \mathrm{~h}$, respectively. The assemblies with different concentrations were added for another $4 \mathrm{~h}$ coincubation. After then, the media were replaced with fresh media containing $10 \%$ serum. Twenty four hours later, the cell culture medium was removed and the cells were washed with phosphate buffered saline (PBS) buffer ( $\mathrm{pH}$ 7.4). Following, the cells were incubated with fresh serum-free media containing $10 \%$ CCK-8 for $2 \mathrm{~h}$, and the absorbance was detected by microplate reader (Bio-Rad 550, USA) under $450 \mathrm{~nm}$.

In Vitro Transfection Efficiency: In vitro gene transfection efficiency was detected on various cells, including HeLa, HepG2, MCF7, and B16 cells, respectively. The cells were seeded in 96-well plates with a density of $1 \times 10^{4}$ cells per well. After $24 \mathrm{~h}$, the medium were removed and $100 \mu \mathrm{L}$ of fresh medium with or without $10 \%$ serum were added. Simultaneously, complexes of gene/assemblies containing 200 ng pEGFP were added per well with different N/P ratios $(10,20,30$, and 40$)$. After $4 \mathrm{~h}$ incubation at $37{ }^{\circ} \mathrm{C}$, the media were replaced by the fresh DMEM containing $10 \%$ serum, and the green fluorescent protein expression was observed by fluorescence microscope (Leica, Germany) after other $44 \mathrm{~h}$. Lipofectamine 2000 and RLS assemblies were acted as control groups.

Intracellular Fluorescence Recovery: The fluorescence recovering assay in cells was observed by CLSM (Leica TCS SP5, Germany). HeLa cells or HepG2 cells were seeded at a density of $1 \times 10^{4}$ cells per well in $35 \mathrm{~mm}$ confocal dish $(\Phi=15 \mathrm{~mm})$ and incubated overnight for attachment. Then the medium was replaced by fresh complete culture medium containing RNS-2/DNA complexes with N/P $=30$ (300 ng of Cy3-labeled pGL3). After coincubation for different time $(2,4,6$, and $8 \mathrm{~h})$, the cells were washed by cold PBS $(\mathrm{pH}=7.4)$ twice to remove the assemblies which did not be taken. Then the nucleus was stained by Hoechst 33342 for 15 min prior to observation. The modified NIR dyes were excited by $663 \mathrm{~nm}$ laser and the channel (dichroic mirror 700-800 nm) was used to detect the emission signals. The intracellular localization of DNA complexes was observed by excitation wavelength at $545 \mathrm{~nm}$ laser and the emission signals of Cy3 were received in Cy3 channel (dichroic mirror 560-620 nm). The FITClabeled PEI condensed Cy3-labeled $\mathrm{PGL} 3$ gene complexes $(\mathrm{N} / \mathrm{P}=10)$ were set as control. FITC was excited at $488 \mathrm{~nm}$ and the emission wavelength of was $520 \mathrm{~nm}$. The excitation and emission wavelengths of Hoechst 33342 were 350 and $461 \mathrm{~nm}$, respectively.

Intracellular Gene Release: The FRET was used to observed intracellular gene release by confocal laser scanning microscope (CLSM, Leica TCS SP5, Germany). HeLa cells were seeded in a $35 \mathrm{~mm}$ confocal dish $(\Phi=15 \mathrm{~mm})$ with a density of $1 \times 10^{4}$ cells per well and incubated overnight and continue to incubate with RLS/DNA complexes with N/P = 10 (300 ng of Cy3 and Cy5 colabeled pGL3) in complete culture medium. After coincubation for different time $(2,4,6$, and $8 \mathrm{~h}$ ), the cells were washed with PBS $(\mathrm{pH}=7.4)$ to remove the assemblies which did not be taken. Then the nucleus was stained by Hoechst 33342 for 15 min prior to observation. The excitation wavelength of $\mathrm{Cy}_{3}$ was $545 \mathrm{~nm}$ and the emission signals of Cy 3 and Cy5 were observed in the Cy3 (dichroic mirror 565-620 nm) and Cy5 (dichroic mirror 655-755 nm) channels, respectively. The excitation and emission wavelengths of Hoechst 33342 were 350 and $461 \mathrm{~nm}$, respectively. PEI condensed Cy3 and Cy5 colabeled pGL3 gene complexes were also used as control.

In Vivo Imaging and Transfection Efficiency: In vivo imaging was observed by CRI Maestro Imaging System (Cambridge Research and Instrumentation Inc., USA). All the animal experiments were conducted with the approval of the Institutional Animal Care and Use Committee of the Animal Experiment Center of Western China Second University Hospital (Chengdu, China) as well as the Regulations for the Administration Affairs Concerning Experimental Animals. Healthy BALB/C nude mice (18-20 g) were lived in a pathogen-free environment according to NIH guidance and fed with sterilized food and distilled water. HeLa cells $\left(1 \times 10^{7}\right)$ were injected into the right flank region of female Balb/c mice to form a xenograft tumor model. The vernier caliper was exploited to measure the size of tumor for the longest $(L)$ and shortest $(W)$ diameters. The volume of tumor was calculated by formula of $V\left[\mathrm{~mm}^{3}\right]=1 / 2 \times L W^{2}$. When the tumor reached 150-200 $\mathrm{mm}^{3}$, the nude mice were randomly divided into two groups $(n=3)$, which received gene/assemblies complexes treatment. For intratumoral injection, mice were treated with $65 \mu \mathrm{g}$ RNS-2 assemblies. Moreover, the complexes of RNS-2/Cy5-labeled DNA with dosage of $5 \mu \mathrm{g}$ DNA were also observed in vivo by intratumoral injection. After injection for $24 \mathrm{~h}$, the mice were sacrificed and the isolated tissues containing heart, liver, spleen, lung, kidney, and tumor were observed by CRI Maestro Imaging System.

For in vivo transfection efficiency, when the volume of tumor grew to $150-200 \mathrm{~mm}^{3}$, the nude mice were randomly divided into two groups $(n=5)$. They were treated with the RNS-2/pEGFP complexes $(\mathrm{N} / \mathrm{P}=30)$ and $\mathrm{RNS}-2 / \mathrm{Cy} 3-\mathrm{pGL} 3$ complexes $(\mathrm{N} / \mathrm{P}=30)$ with a dosage of $15 \mu \mathrm{g}$ DNA through intratumoral injection, respectively. The mice were sacrificed after $48 \mathrm{~h}$ and the isolated tissues including liver, lung, kidney, and tumor were washed with ice-cold PBS buffer $(\mathrm{pH}=7.4)$. These isolated tissues were observed by CRI Maestro Imaging System first and then were immediately froze and cut into $10 \mu \mathrm{m}$ thick sections. These frozen sections were observed by fluorescence microscope (Leica, Germany).

In Vivo Distribution and Biocompatibility: In order to assess the premature leakage of assemblies and distribution in vivo, the complexes of RNS- 2 assemblies condensing $15 \mu \mathrm{g}$ Cy5-labeled DNA with N/P $=30$ were intravenously injected into mice. The premature leakage profile was detected using CRI Maestro Imaging System. At $24 \mathrm{~h}$ postintravenous injection, the mouse organs were removed. Fluorescence signals for $\mathrm{Cy} 5$ and NIR were detected using CRI Maestro Imaging System, respectively.

A high dose of RNS-2/pEGFP complexes $(\mathrm{N} / \mathrm{P}=30)$ with a dosage $75 \mu \mathrm{g}$ DNA was injected via tail vein using saline treated as control group. After $48 \mathrm{~h}$, blood was collected through retro-orbital bleeding in the two treatment groups of nude mice. Plasma was obtained by centrifugation at $3000 \mathrm{rpm}$ for $15 \mathrm{~min}$ twice for blood biochemistry analysis. The plasma levels of aspartate aminotransferase and alanine aminotransferase were measured to evaluate liver function. Renal function was investigated by quantifying blood urea nitrogen and creatinine levels. Blood routine and serum biochemical indicators were measured by auto hematology analyzer (TEK-II MINI). Organs including heart, liver, spleen, lung, and kidney were drawn out, fixed immediately in paraformaldehyde and embedded in paraffin, and serially cut for histopathological examination by the hematoxylin and eosin (H\&E) staining.

Statistical Analysis: Data were performed at least in triplicate and presented as the mean \pm standard deviation (mean $\pm S$. D.) for three or five independent samples. Statistical analysis was carried out by analysis of variance tests with Microsoft office software. The relative fold change of fluorescent intensity was pseudocolored using the heatmap feature in GraphPad Prism 7.03.

\section{Supporting Information}

Supporting Information is available from the Wiley Online Library or from the author.

\section{Acknowledgements}

H.L. and X.C. contributed equally to this work. This study was supported by the National Key Research and Development Plan of China (2017YFC1104601), the National Natural Science Foundation of China (NSFC, Nos. 81571794 and 81873921), Sino-German cooperation group project (GZ1512) and Sichuan Science and Technology Program (2019JDJQ0027 and 2019JDJQ0004), the Fundamental Research Funds for the Central Universities (2012017yjsy222) and Spark innovation Project of Sichuan University (2018SCUH0045 and 2018SCUH0033), Miaozi Project in Science and Technology Innovation Program of Sichuan Province (2019071). 


\section{Conflict of Interest}

The authors declare no conflict of interest.

\section{Keywords}

gene delivery, indocyanine green analogues, near-infrared fluorescence imaging, precise real-time image, theranostic systems

Received: November 12, 2019

Revised: December 17, 2019

Published online: February 5, 2020

[1] T. Frohlich, D. Edinger, R. Klager, C. Troiber, E. Salcher, N. Badgujar, I. Martin, D. Schaffert, A. Cengizeroglu, P. Hadwiger, H. P. Vornlocher, E. Wagner, J. Controlled Release 2012, 160, 532.

[2] X. Guan, Z. Guo, T. Wang, L. Lin, J. Chen, H. Tian, X. Chen, Biomacromolecules 2017, 18, 1342.

[3] Y. Li, Y. Li, X. Zhang, X. Xu, Z. Zhang, C. Hu, Y. He, Z. Gu, Theranostics 2016, 6, 1293.

[4] X. Cai, R. Jin, J. Wang, D. Yue, Q. Jiang, Y. Wu, Z. Gu, ACS Appl. Mater. Interfaces 2016, 8, 5821.

[5] J. Li, C. Zheng, S. Cansiz, C. Wu, J. Xu, C. Cui, Y. Liu, W. Hou, Y. Wang, L. Zhang, I. T. Teng, H. H. Yang, W. Tan, J. Am. Chem. Soc. 2015, 137, 1412.

[6] X. Liu, J. Xiang, D. Zhu, L. Jiang, Z. Zhou, J. Tang, X. Liu, Y. Huang, Y. Shen, Adv. Mater. 2016, 28, 1743.

[7] Y. Li, H. Bai, H. Wang, Y. Shen, G. Tang, Y. Ping, Nanoscale 2017, 10, 203.

[8] M. Naito, N. Yoshinaga, T. Ishii, A. Matsumoto, Y. Miyahara, K. Miyata, K. Kataoka, Macromol. Biosci. 2018, 18, 1700357.

[9] Z. Zhou, M. Zhang, Y. Liu, C. Li, Q. Zhang, D. Oupicky, M. Sun, Biomacromolecules 2018, 19, 3776.

[10] C. Y. Quan, J. X. Chen, H. Y. Wang, C. Li, C. Chang, X. Z. Zhang, R. X. Zhuo, ACS Nano 2010, 4, 4211.

[11] Y. Nie, D. Schaffert, W. Rödl, M. Ogris, E. Wagner, M. Günther, J. Controlled Release 2011, 152, 127.

[12] Y. Nie, M. Günther, Z. Gu, E. Wagner, Biomaterials 2011, 32, 858.

[13] Q. Jiang, Y. Nie, X. Chen, Y. He, D. Yue, Z. Gu, Adv. Funct. Mater. 2017, 27, 1701571

[14] H. Zhao, J. Duan, Y. Xiao, G. Tang, C. Wu, Y. Zhang, Z. Liu, W. Xue, Chem. Mater. 2018, 30, 3438.

[15] X. Chen, J. Yang, H. Liang, Q. Jiang, B. Ke, Y. Nie, J. Mater. Chem. B 2017, 5, 1482.

[16] G. Shim, S. Ko, D. Kim, Q. V. Le, G. T. Park, J. Lee, T. Kwon, H. G. Choi, Y. B. Kim, Y. K. Oh, J. Controlled Release 2017, 267, 67.

[17] Q. Jiang, D. Yue, Y. Nie, X. Xu, Y. He, S. Zhang, E. Wagner, Z. Gu, Mol. Pharmaceutics 2016, 13, 1809.

[18] Y. He, Y. Nie, G. Cheng, L. Xie, Y. Shen, Z. Gu, Adv. Mater. 2014, 26, 1534.

[19] H. Wang, X. Li, B. W.-C. Tse, H. Yang, C. A. Thorling, Y. Liu, M. Touraud, J. B. Chouane, X. Liu, M. S. Roberts, Theranostics 2018, 8, 1227.

[20] X. Liu, M. Wu, Q. Hu, H. Bai, S. Zhang, Y. Shen, G. Tang, Y. Ping, ACS Nano 2016, 10, 11385.

[21] Z. Sheng, D. Hu, M. Zheng, P. Zhao, H. Liu, D. Gao, P. Gong, G. Gao, P. Zhang, Y. Ma, L. Cai, ACS Nano 2014, 8, 12310.

[22] H. Ding, F. Wu, Theranostics 2012, 2, 1040.

[23] Z. Ma, X. Jia, J. Bai, Y. Ruan, C. Wang, J. Li, M. Zhang, X. Jiang, Adv. Funct. Mater. 2017, 27, 1604258.

[24] D. Gyawali, S. Zhou, R. T. Tran, Y. Zhang, C. Liu, X. Bai, J. Yang, Adv. Healthcare Mater. 2014, 3, 182.

[25] J. Croissant, J. I. Zink, J. Am. Chem. Soc. 2012, 134, 7628.
[26] S. U. Hettiarachchi, B. Prasai, R. L. McCarley, J. Am. Chem. Soc. 2014, 136, 7575.

[27] R. Blau, Y. Epshtein, E. Pisarevsky, G. Tiram, S. Israeli Dangoor, E. Yeini, A. Krivitsky, A. Eldar-Boock, D. Ben-Shushan, H. Gibori, A. Scomparin, O. Green, Y. Ben-Nun, E. Merquiol, H. Doron, G. Blum, N. Erez, R. Grossman, Z. Ram, D. Shabat, R. Satchi-Fainaro, Theranostics 2018, 8, 3437.

[28] Q. Liu, S. Xu, C. Niu, M. Li, D. He, Z. Lu, L. Ma, N. Na, F. Huang, H. Jiang, J. Ouyang, Biosens. Bioelectron. 2015, 64, 119.

[29] H. Kim, G. Kwak, K. Kim, H. Y. Yoon, I. C. Kwon, Biomaterials 2019 213, 119207.

[30] M. Gao, F. Yu, C. Lv, J. Choo, L. Chen, Chem. Soc. Rev. 2017, 46, 2237.

[31] L. Quan, S. Liu, T. Sun, X. Guan, W. Lin, Z. Xie, Y. Huang, Y. Wang, X. Jing, ACS Appl. Mater. Interfaces 2014, 6, 16166.

[32] X. Liu, B. Chen, X. Li, L. Zhang, Y. Xu, Z. Liu, Z. Cheng, X. Zhu, Nanoscale 2015, 7, 16399.

[33] Z. Guo, Y. Zou, H. He, J. Rao, S. Ji, X. Cui, H. Ke, Y. Deng, H. Yang, C. Chen, Y. Zhao, H. Chen, Adv. Mater. 2016, 28, 10155.

[34] H. J. Yoon, H. S. Lee, J. H. Jung, H. K. Kim, J. H. Park, ACS Appl. Mater. Interfaces 2018, 10, 6118.

[35] H. Pan, C. Zhang, T. Wang, J. Chen, S.-K. Sun, ACS Appl. Mater. Interfaces 2019, 11, 2782

[36] U. Lächelt, E. Wagner, Chem. Rev. 2015, 115, 11043.

[37] Y. Tu, F. Peng, A. Adawy, Y. Men, L. K. Abdelmohsen, D. A. Wilson, Chem. Rev. 2016, 116, 2023.

[38] H. Liang, A. Hu, X. Chen, R. Jin, K. Wang, B. Ke, Y. Nie, J. Mater. Chem. B 2019, 7, 915.

[39] Y. Chen, Z. Li, H. Wang, Y. Wang, H. Han, Q. Jin, J. Ji, ACS Appl. Mater. Interfaces 2016, 8, 6852.

[40] F. L. Tansi, R. Ruger, C. Bohm, R. E. Kontermann, U. K. Teichgraeber, A. Fahr, I. Hilger, Biomaterials 2016, 88, 70.

[41] F. He, Y. Tang, S. Wang, Y. Li, D. Zhu, J. Am. Chem. Soc. 2005, 127, 12343.

[42] C. A. Lin, R. A. Sperling, J. K. Li, T. Y. Yang, P. Y. Li, M. Zanella, W. H. Chang, W. J. Parak, Small 2008, 4, 334.

[43] A. Yamada, Y. Hiruta, J. Wang, E. Ayano, H. Kanazawa, Biomacromolecules 2015, 16, 2356.

[44] C. Yan, Z. Guo, Y. Shen, Y. Chen, H. Tiana, W. Zhu, Chem. Sci. 2018, 9, 4959.

[45] I. Koltover, T. Salditt, J. O. Rädler, C. R. Safinya, Science 1998, 281, 78.

[46] H. S. Choi, K. Nasr, S. Alyabyev, D. Feith, J. H. Lee, S. H. Kim Y. Ashitate, H. Hyun, G. Patonay, L. Strekowski, M. Henary, J. V. Frangioni, Angew. Chem., Int. Ed. 2011, 50, 6258.

[47] M. Piest, J. F. J. Engbersen, J. Controlled Release 2010, 148, 83.

[48] Y. Xue, J. Tian, Z. Liu, J. Chen, M. Wu, Y. Shen, W. Zhang, Biomacromolecules 2019, 20, 2796.

[49] G. Cheng, Y. He, L. Xie, Y. Nie, B. He, Z. Zhang, Z. Gu, Int. J. Nanomed. 2012, 7, 3991.

[50] Y. He, G. Cheng, L. Xie, Y. Nie, B. He, Z. Gu, Biomaterials 2013, 34, 1235.

[51] S. Raffy, J. Teissié, Biophys. J. 1999, 76, 2072.

[52] M. L. Briuglia, C. Rotella, A. McFarlane, D. A. Lamprou, Drug Delivery Transl. Res. 2015, 5, 231.

[53] Y. Wen, Z. Zhang, J. Li, Adv. Funct. Mater. 2014, 24, 3874.

[54] B. Wang, R. M. Zhao, J. Zhang, Y. H. Liu, Z. Huang, Q. Y. Yu, X. Q. Yu, Eur. J. Med. Chem. 2017, 136, 585.

[55] C. L. Grigsby, K. W. Leong, J. R. Soc., Interface 2010, 7, S67.

[56] J. Park, J. Park, Y. Pei, J. Xu, Y. Yeo, Adv. Drug Delivery Rev. 2016, 104, 93.

[57] J. T. Alander, I. Kaartinen, A. Laakso, T. Pätilä, T. Spillmann, V. V. Tuchin, M. Venermo, P. Välisuo, Int. J. Biomed. Imaging 2012, 2012, 1.

[58] Y.-P. Ho, H. H. Chen, K. W. Leong, T.-H. Wang, J. Controlled Release 2006, 116, 83.

[59] Q. Jiang, X. Chen, H. Liang, Y. Nie, R. Jin, M. Barz, D. Yue, Z. Gu, Nanoscale Adv. 2019, 1, 498 